\title{
Asbesto (amianto) e doença: revisão do conhecimento científico e fundamentação para uma urgente mudança da atual política brasileira sobre a questão
}

\author{
Asbestos and disease: state-of-the-art review \\ and a rationale for urgent change in current \\ Brazilian policy
}

René Mendes 1

1 Departamento de Medicina Preventiva e Social, Faculdade de Medicina, Universidade Federal de Minas Gerais. Av. Alfredo Balena 190, Belo Horizonte, $M G$ 30130-100, Brasil.

\begin{abstract}
This paper is a state-of-the-art review of scientific knowledge on both the health effects of asbestos fiber inhalation and possibilities for safe and sustainable prevention, from an ethical, political, and technological point of view. The author provides scientific background and arguments from the ongoing discussion in Brazil concerning the need to redefine current asbestos policy, in order to establish a more advanced and appropriate policy whose priority is the protection of life, human health, and the environment. The first part deals with several technological and economic aspects of asbestos-chrysotile. In the second part, the author presents and discusses a bibliographic review of the construction of scientific knowledge on the health effects of asbestos fibers, first within an international perspective, and then (in the third part), from a Brazilian view. The fourth part analyzes the current debate on the fibrogenicity and carcinogenicity of asbestos-chrysotile. Some current responses from the international community towards the asbestos-chrysotile ban are also discussed. Finally, the author discusses the historical inadequacy of Brazilian asbestos policy and the urgent need to revise it to include a ban on asbestos-chrysotile in this country.
\end{abstract}

Key words Asbestos; Asbestosis; Pleural Mesothelioma; Lung Neoplasms; Occupational Health

Resumo Neste artigo revê-se o estado do conhecimento científico quanto aos efeitos da inalação de fibras de asbesto (amianto) na saúde humana e sua prevenção. Propõe-se a fundamentação científica do debate que se faz no Brasil, visando alterar a política governamental sobre a questão, de modo a priorizar a defesa da vida, da saúde e do meio-ambiente. No início, são discutidos aspectos tecnológicos e econômicos acerca do asbesto e, em especial, da crisotila. A seguir, explana-se a evolução do conhecimento científico internacional sobre os efeitos da inalação de fibras de asbesto na saúde. Após isso, descreve-se o conhecimento nacional acerca dos danos oriundos do amianto, concluindo-se que as doenças descritas no exterior constam de nossa literatura médica há tempos. Na seqüência, enfoca-se o debate sobre a nocividade do asbesto-crisotila, o qual aponta para a sua confirmação. Depois, expõem-se as respostas da comunidade internacional à questão e a mobilização pela proibição do asbesto. Por fim, estuda-se a inadequação da posição brasileira e explicita-se a necessidade de revisão urgente.

Palavras-chave Asbesto; Asbestose; Mesotelioma de Pleura; Neoplasias Pulmonares; Saúde Ocupacional 


\section{Introdução}

O presente trabalho constitui-se numa revisão do estado atual do conhecimento científico sobre os efeitos da inalação de fibras de asbesto (amianto) na saúde humana, bem como acerca da possibilidade de sua prevenção em bases seguras e sustentáveis do ponto de vista ético, político e tecnológico. Tem por finalidade principal fundamentar cientificamente a discussão que se faz atualmente em nosso país, visando a imediata modificação da política governamental de manejo da questão do asbesto (amianto), adotada pelo Brasil, substituindo-a por uma política que priorize a defesa da vida, da saúde e do meio ambiente.

O trabalho inicia com uma breve nota sobre alguns aspectos tecnológicos e econômicos do asbesto (amianto), com destaque para a crisotila. Aprofunda, em seguida, a tarefa de revisão bibliográfica crítica, sobre o "estado da arte" relativo ao conhecimento dos efeitos das fibras de asbesto (amianto) sobre a saúde, partindo da evolução do conhecimento científico internacional, para depois tentar avaliar o grau de conhecimento dos problemas do asbesto (amianto) no Brasil. Introduz, a seguir, o debate concernente à nocividade da variedade crisoti$l a$, ainda extraída, industrializada, comercializada e também exportada pelo Brasil. São, em seguida, identificadas e discutidas as respostas da comunidade internacional ao problema da nocividade do asbesto (amianto) e a mobilização pelo seu banimento (proibição total e completa). Na última parte do trabalho, discute-se a inadequação e não-sustentabilidade do atual posicionamento brasileiro sobre o problema e a necessidade urgente de sua revisão.

\section{Alguns aspectos tecnológicos e econômicos sobre o asbesto (amianto), com destaque para a crisotila}

Asbesto e amianto são nomes comerciais de um grupo heterogêneo de minerais facilmente separáveis em fibras. Apresentando composições químicas e cristalográficas diversas, essas fibras têm usos e classificações comerciais que variam muito de um mineral para outro. Listam-se mais de 350 minerais com estrutura fibrosa, encontrados como minerais essenciais ou acessórios nas rochas magmáticas e metamórficas (Becklake, 1998; Scliar, 1998).

Os amiantos ou asbestos pertencem a dois grupos de minerais: a crisotila (asbesto branco), representando a variedade fibrosa do grupo das serpentinas, e os minerais fibrosos do grupo dos anfibólios: crocidolita (asbesto azul), amosita (asbesto marrom), antofilita, actinolita e tremolita (Brasil, 1991; Scliar, 1998).

A crisotila (silicato hidratado de magnésio) apresenta-se na forma de fibras flexíveis, finas e sedosas, com comprimento que varia de menos de 1 até 40 milímetros. Resiste ao calor e caracteriza-se por ser facilmente tecida. Um quilograma de fibra pode produzir até $20 \mathrm{mil} \mathrm{me-}$ tros de fio. Dos cerca de quarenta países que têm reservas naturais de crisotila, 25 extraem-na e cerca de sete são atualmente responsáveis por cerca de $95 \%$ da produção mundial: Canadá (Quebec, British Columbia e Newfoundland), Rússia (Montes Urais), Brasil (Canabrava, Goiás), Casaquistão, China (Província de Szchwan), Zimbábue e África do Sul (Pigg, 1994; Crowson, 1996; Becklake, 1998; IPCS, 1998; Scliar, 1998).

A produção mundial de asbesto é atualmente representada, em mais de $98 \%$, pela variedade crisotila, a qual, no Brasil, representa $100 \%$ do amianto atualmente minerado. Entre 1964 e 1973, a produção mundial de asbesto aumentou cerca de $50 \%$, tendo alcançado o pico de cinco milhões de toneladas/ano em meados da década de 70. Desde então passou a cair, até atingir um nível estimado hoje na ordem de 2,6 milhões de toneladas/ano. O declínio que permanece e propende a acentuar-se está diretamente associado à cronologia das crescentes restrições de extração e importação do amianto, que tendem a ampliar-se, no mundo em função de sua nocividade.

No Brasil - quinto produtor mundial de $\mathrm{cri}$ sotila - há jazidas de amianto (crisotila e anfibólios) nos estados de Goiás, Minas Gerais, Bahia e Piauí. A primeira mineração de asbestocrisotila no país, utilizando técnicas modernas, foi desenvolvida pela SAMA - S.A. Mineração de Amianto, na Mina de São Félix, no Município de Poções, na Bahia, a partir de 1940, permanecendo ativa até 1967, quando suas reservas se esgotaram. Atualmente, a totalidade do amianto crisotila é minerada e processada na Mina de Cana Brava, em Minaçu, Goiás (Nunes, 1988).

Com as restrições ao asbesto nos países da Europa Ocidental e nos Estados Unidos, o mercado internacional de venda de fibras de asbesto-crisotila e de produtos de fibrocimento vem crescentemente se dirigindo aos países que ainda não introduziram as restrições ao asbesto, isto é, os grandes países asiáticos que não mineram em seu território - Japão (maior consumidor de asbesto e de produtos de asbesto do mundo), Índia, Taiwan, Coréia -, aos países do Sudeste Asiático (principalmente Tailândia e Malásia), países latino-americanos (princi- 
palmente México, Argentina, Chile, Uruguai e países centro-americanos) e países africanos (principalmente Nigéria e Angola) (Lemen \& Bingham, 1994; Frank, 1995b; IPCS, 1998; U. S. Department of the Interior, 1998; Collegium Ramazzini, 1999a, 1999b; Maltoni, 1999).

Os usos do asbesto-crisotila têm variado com o tempo, como bem mostram diversos estudos tecnológicos e mercadológicos, de modo que o perfil das exposições ocupacionais também evoluiu no correr da história do amianto de modo significativo. De mais de três mil finalidades de uso que se atribuía ao amianto no passado, elas estão atualmente concentradas em relativamente poucas, onde os produtos de cimento-amianto ou fibrocimento representam cerca de $85 \%$ do consumo destas fibras. Estimase que os materiais de fricção consumam cerca de $19 \%$ da produção de crisotila; a fabricação de produtos têxteis cerca de $3 \%$; a produção de juntas de vedação e gaxetas cerca de $2 \%$; e os restantes 1\% têm outros usos (Pigg, 1994; Becklake, 1998; IPCS, 1998; Scliar, 1998).

Em relação aos produtos de cimento-amianto ou fibrocimento, estima-se que sua produção, desenvolvida em mais de cem países, alcance entre 27 a 30 milhões de toneladas por ano. Estes produtos contêm, em média, 10 a $15 \%$ de asbesto (amianto). Correspondem a cinco tipos principais de produtos: placas onduladas para telhados; placas planas para divisórias, revestimento de interiores ou exteriores; caixas d'água; canos para água em baixa pressão; canos ou tubos para alta pressão (Pigg, 1994; Fernandez Jr., 1999).

Em decorrência das crescentes restrições aos usos do amianto em razão de sua elevada nocividade para a saúde humana, buscam-se, no mundo inteiro, produtos alternativos, naturais ou sintéticos, que substituam os seus usos e que, ao mesmo tempo, não acarretem riscos tão elevados à saúde humana. A lista de substitutos do amianto é muito grande, e alguns destes produtos atendem plenamente as especificações tecnológicas e, de modo satisfatório, as especificações de proteção da saúde humana, enquanto outros estão sendo desenvolvidos e avaliados em seus riscos (Gibbs, 1994; INSERM, 1998; Foà \& Basilico, 1999).

\section{Evolução do conhecimento científico sobre os efeitos da inalação das fibras de asbesto (amianto) sobre a saúde}

As observações sobre os efeitos nocivos da inalação de poeiras de asbesto sobre a saúde humana são tão antigas quanto os multiformes usos destas fibras. Mais recentemente, já no advento da Medicina dita científica, deve-se ao médico inglês H. Montagne Murray, a descrição, publicada em 1907, da asbestose, doença responsável pela morte de um trabalhador exposto ao asbesto em atividades de fiação. A comprovação anatomopatológica obtida na necropsia revelava a essência do processo pneumoconiótico, caracterizada pela presença de extensas áreas cicatriciais nos pulmões. Descrições como a de Murray sucederam-se nas décadas seguintes tanto no Reino Unido como nos Estados Unidos, na Alemanha, na França, na Itália e no Canadá (Algranti, 1986; Mendes, 1986, 1987; Gottlieb, 1989; Becklake, 1998).

Cooke, em 1924, foi o primeiro a estabelecer claramente, mediante quadro clínico do paciente e achados de necropsia, a correlação entre ocupação e doença grave, por ele denominada, em 1927, "fibrose pulmonar", na verdade, o mesmo tipo de pneumoconiose grave asbestose - nome com que passou a ser conhecida esta doença (Cooke, 1927).

Em 1930, Merewether e Price apresentaram detalhado relatório ao parlamento britânico, enfocando estudos epidemiológicos referentes às doenças causadas pelo asbesto e chamando a atenção aos métodos de prevenção e controle com base na supressão e eliminação de poeiras. Este estudo resultou na adoção de medidas de segurança que deveriam ser postas em prática nos locais de trabalho e que seriam objeto de inspeções médicas. Em 1934, o médico Thomas Legge, grande propulsor da inspeção médica de fábricas na Inglaterra, propôs a inclusão da asbestose na lista de doenças profissionais então vigente (Gottlieb, 1989).

Em 1935, Gloyne, patologista britânico, descreveu o potencial carcinogênico do asbesto. Suas descrições pioneiras apontavam para a associação entre carcinoma pulmonar de células escamosas à presença de asbestose (Gloyne, 1935). Publicações norte-americanas do mesmo ano confirmavam tais achados de câncer de pulmão relacionados à exposição ao asbesto (Lynch \& Smith, 1935).

Em 1949, Merewether, no Reino Unido, em seu Relatório Anual da Chefia da Inspeção das Fábricas, relativo ao ano de 1948, informava haver observado que cerca de $13 \%$ dos pacientes com asbestose haviam falecido por câncer de pulmão (Gottlieb, 1989; Becklake, 1998).

Coube ao epidemiologista britânico Richard Doll, em 1955, estabelecer definitivamente a associação causal entre a exposição ocupacional ao asbesto e câncer de pulmão. Em trabalho que veio a tornar-se paradigma metodológico clássico em Epidemiologia, Doll demons- 
trou que a freqüência de câncer pulmonar em trabalhadores da indústria têxtil expostos ao asbesto durante vinte anos, ou mais, era dez vezes a esperada na população geral (Doll, 1955). Pesquisadores do Mount Sinai Hospital e da respectiva Faculdade de Medicina, em Nova York, ampliaram os estudos acerca desta associação, demonstrando, de modo irrefutável, o excesso de mortes por câncer de pulmão, em 17.800 trabalhadores de isolamento térmico: mais de $20 \%$ dos expostos vieram a falecer de câncer de pulmão (Selikoff et al., 1964, 1979; Selikoff \& Lee, 1978).

Por sua vez, foram-se acumulando, a partir da década de 30, evidências sugestivas da associação causal entre exposição ao asbesto e desenvolvimento de tumores da pleura e/ou peritônio extremamente malignos, os mesoteliomas (Gloyne, 1933). Trabalhos científicos da década de 40 e de 50 apontavam para esta possibilidade de associação causal, o que foi confirmado pelos estudos realizados por Wagner et al. (1960) na África do Sul. Estes autores publicaram o estudo relativo a 33 casos de mesotelioma, 32 dos quais haviam trabalhado em minas de asbesto (à época, com a variedade crocidolita) e/ou residido perto das minas onde se extraíam fibras deste minério. Deste estudo advieram as observações - hoje confirmadas - respeitantes à possibilidade de desenvolvimento de mesotelioma maligno mesmo após curtas exposições ou de exposições em baixas doses, mas, via de regra, após longo tempo de latência. Em Londres, Newhouse \& Thompson (1965), com base em estudo de 76 casos e utilizando metodologia epidemiológica elegante, confirmaram a forte associação causal entre mesotelioma de pleura ou peritônio e exposição pregressa a asbesto, quer de natureza ocupacional, quer pela proximidade das residências às plantas industriais que o processam.

Descreveram-se também casos de mesotelioma maligno de pleura e/ou peritônio após períodos de latência extremamente longos em torno de 30 a 35 anos, ou mais -, bem como casos em crianças expostas a fibras de asbesto nas proximidades das fábricas. Foram também narrados casos em mulheres e em crianças que, no interior de seus domicílios, foram expostas a fibras de asbesto trazidas na roupa de cônjuges-trabalhadores ocupacionalmente expostos. Estes achados, por sua peculiaridade e extrema gravidade, serviram para reforçar a aparente não-dependência de dose-resposta na relação causal entre asbesto e mesoteliomas (IARC, 1977; Selikoff et al., 1979; Mendes, 1986, 1987; Gottlieb, 1989; Becklake, 1998).
Ainda em relação aos mesoteliomas malignos, é conhecida a predominância da localização pleural - cerca de $81 \%$ de todos os casos -, seguida da localização peritonial, estimada em $15 \%$ de todos os casos. As outras localizações pericárdio, ovários e bolsa escrotal -, juntas, representam cerca de $4 \%$ de todos os casos (Gottlieb, 1989).

Diversos trabalhos científicos mostram que a incidência destes tumores altamente malignos, outrora extremamente raros, vem aumentando aceleradamente em inúmeros países do mundo, ao que tudo indica, em decorrência da exposição ocupacional e/ou ambiental ao asbesto (Hinds, 1978; Javholm et al., 1990; Cullem \& Baloyi, 1991; Bégin et al., 1992; Musk et al., 1992; Englund, 1995; Frank, 1995b; Huuskonen et al., 1995; Lemen, 1995; Richter et al., 1995; Karjalainen et al., 1997).

Outras neoplasias malignas têm sido associadas à exposição ao asbesto, tais como o câncer de laringe, câncer de orofaringe, câncer de estômago, câncer colo-retal, e câncer de rim, localizações aparentemente menos influenciadas pelo tabagismo. Destas, a descrita com mais freqüência é a laringe (Gottlieb, 1989; Becklake, 1998; Goodman et al., 1999).

\section{Conhecimento dos problemas causados pelo asbesto no Brasil}

O conhecimento dos problemas de saúde causados pelo asbesto no Brasil advém da detecção de casos de doenças - em especial, da $a s$ bestose - enquanto doença profissional, específica e clássica, e do mesotelioma maligno de pleura, na qualidade de doença epidemiologicamente "relacionada com o trabalho" (Costa et al., 1983; Algranti, 1986, 1988; Mendes, 1986, 1987; Nogueira, 1988a, 1988b; Bedrikow, 1989; De Capitani, 1994; Algranti et al., 1995).

Três, basicamente, têm sido as abordagens e as estratégias para detecção da asbestose: (a) estudos de prevalência, com base em radiografias pulmonares realizadas em trabalhadores sabidamente expostos; (b) casuísticas de serviços especializados em Pneumologia, Pneumologia Ocupacional ou Doenças Profissionais em geral; (c) busca ativa de casos em grupos de trabalhadores sintomáticos - respiratórios ou com outras doenças pulmonares concorrentes evolutivas ou que mascaram a asbestose.

No caso do mesotelioma de pleura - por sua relativa raridade até o momento e em virtude de sua longa latência no que diz respeito à exposição ao asbesto que o induz -, a experiência brasileira é ainda constituída de casos avulsos, 
detectados em serviços de Pneumologia, onde o antecedente de exposição ocupacional ao asbesto é recuperado pela história profissional. Ao contrário de outros países, em nosso meio não se conhecem resultados de estudos de seguimento de longo prazo de "coortes de expostos”, com tempo suficiente para que estas se extingam pela mortalidade, e que esta seja analisada segundo sua causa básica. Aliás, a extremamente elevada letalidade dos mesoteliomas malignos faz com que seu estudo se confunda com estudos de mortalidade, abrindo, neste caso, outra alternativa de abordagem metodológica.

Isto posto, vale o registro de que, ao que tudo indica, a primeira referência no Brasil sobre as doenças relacionadas ao asbesto está registrada no Boletim no 98, do Departamento Nacional da Produção Mineral, publicado em 1956, sob o título Higiene das Minas - Asbesto$s e$, monografia elaborada pelos médicos Carlos Martins Teixeira e Manoel Moreira. Trata-se de estudo realizado nas minas de asbesto da FAMA (Eternit), no Município de Nova Lima, Minas Gerais e na usina de beneficiamento do minério. Após efetuarem minucioso estudo clínico e radiológico de oitenta trabalhadores, os autores identificaram seis casos de fibrose nas bases pulmonares compatíveis com formas iniciais de asbestose (Departamento Nacional da Produção Mineral, 1956).

Passados quase vinte anos, o Prof. Diogo Pupo Nogueira e colaboradores publicaram na literatura médica, sob o sugestivo título "Asbestose no Brasil: Um Risco Ignorado", um caso de asbestose proveniente da indústria de cimentoamianto, onde o paciente trabalhara por 22 anos, inicialmente como simples operário mas, progressivamente e através dos anos, como encarregado, contramestre e chefe geral. Após discutirem, de modo detalhado, as alterações clínicas, radiológicas e funcionais, os autores chamaram a atenção para a importância da anamnese ocupacional, ensinada primeiramente por Bernardino Ramazzini (1633-1714), ainda tão poucas vezes posta em prática no exercício da profissão médica (Nogueira et al., 1975). Assim, a propósito deste caso de asbestose detectado, os autores expressavam sua opinião de que "é, obviamente, impossível que casos semelhantes não existam, no Brasil, em trabalhadores expostos ao asbesto. Portanto, deve-se acreditar que numerosos outros casos, semelhantes ao presente, estejam sendo examinados e rotulados como portadores de outras patologias" (Nogueira et al., 1975:420).

Em 1976, o Dr. Manoel Ignácio Rollemberg dos Santos - cirurgião de tórax e médico do tra- balho - descreveu com um colaborador mais três casos de asbestose relacionados com diferentes ambientes profissionais: fábrica de tintas, fábrica de isolantes térmicos e moinho de beneficiamento de amianto (Santos \& Machado, 1976). Mais tarde, o mesmo autor publicava trabalho sugestivamente intitulado "Asbestose, a Verdade dos Diagnósticos” (Santos, 1979; Santos \& Mendes, 1980).

Tem-se conhecimento de mais quatro casos de asbestose todavia não publicados, apresentados em reunião científica da Associação Paulista de Medicina, em 1976, pelo Dr. Pedro Augusto Zaia, do Serviço Social da Indústria (SESI) de São Paulo (comunicação pessoal).

Em 1980, o Prof. Reynaldo Quagliato Júnior, do Serviço de Pneumologia da Faculdade de Ciências Médicas da Universidade Estadual de Campinas (UNICAMP), publicou comunicação científica relativa a um caso de asbestose proveniente da indústria de cimento-amianto, onde o paciente havia trabalhado por 12 anos (Quagliato Jr., 1980).

Lyra, em 1982, publicou um estudo sob o título "Inquérito Preliminar de Risco de Asbestose em uma Indústria de Lona de Freios", relatando resultados de avaliação médica e ambiental. Entre os trabalhadores examinados, foram encontrados quatro casos prováveis de asbestose pulmonar, inclusive um caso de mesotelioma (Lyra, 1982).

Seguem-se os estudos do Prof. José Luiz Riani Costa - da Faculdade de Ciências Médicas da UNICAMP à época de seu estudo -, que foi procurar casos de asbestose em registros de segurados da Previdência Social afastados por “pneumopatias crônicas”. Sua Dissertação de Mestrado, apresentada em 1983, enfocou os resultados desta metodologia de trabalho, os quais mostraram que, em 86 trabalhadores da indústria de cimento-amianto, da região de Leme, São Paulo, com mais de dez anos de exposição, foram detectados 14 casos de asbestose $(16,3 \%)$ (Costa, 1983, 1984; Costa \& Ferreira, 1984; Ferreira Jr., 1986).

Entre os trabalhos que se seguiram do mesmo grupo de pesquisadores, um deles, na forma de estudo do "estado-da-arte", intitulado "Asbesto e Doença: Introdução ao Problema no Brasil", concluía que "o número de expostos está crescendo rapidamente em nosso país. No momento atual, estima-se em aproximadamente vinte mil o número de trabalhadores expostos. A população não ocupacionalmente exposta (e portanto sujeita ao risco de mesotelioma) é incalculável, mas certamente é várias vezes maior do que o número de trabalhadores expostos. Considerando-se os dados acima e ofato de 
que as atividades ligadas ao asbesto já existem no Brasil há cerca de 30 anos, é lícito supor que haja considerável número de casos de asbestose, mesotelioma e câncer relacionado a asbesto, que não estão sendo devidamente diagnosticados" (Costa et al., 1983:20).

O Prof. Diogo Pupo Nogueira - confirmando seu alerta de 1975 ("Asbestose no Brasil: Um Risco Ignorado") e vinculando-o aos achados de 1983 - escrevia o Editorial do número da $R e$ vista da Associação Médica Brasileira que publicou o trabalho de Costa et al. (1983), intitulando-o: “Asbestose: Um Grave Risco Ainda Ignorado no Brasil”. (Nogueira, 1983) (Grifos nossos).

Em 1986, o Comitê de Estudos do Amianto (CEA) - com o apoio da Secretaria de Segurança e Medicina do Trabalho do Ministério do Trabalho, Fundação Jorge Duprat Figueiredo de Segurança e Medicina do Trabalho (Fundacentro), Confederação Nacional dos Trabalhadores da Indústria (CNTI), Confederação Nacional da Indústria (CNI), Serviço Social da Indústria/ Departamento Nacional (SESI/DN) e Associação Brasileira do Amianto (ABRA) - realizou em Brasília, Distrito Federal, no mês de julho, o "Seminário Nacional Sobre Exposição Ocupacional ao Asbesto", que contou com a presença de 180 inscritos, além de convidados e conferencistas. Os 12 trabalhos apresentados nesse evento constituíram número inteiro da Revista Brasileira de Saúde Ocupacional, vol. 16, n. 63 (1988), dos quais citam-se alguns trabalhos publicados que se tornaram mais conhecidos, como os de Algranti (1988), Amâncio et al. (1988), Giannasi (1988), Giannasi et al. (1988), Monizde-Aragão et al. (1988), Nogueira (1988a, 1988b), entre outros.

No estudo desenvolvido em três indústrias de cimento-amianto no Estado de São Paulo produtoras de telhas, caixas d'água etc. -, a presença de asbestose em 5,8\% dos trabalhadores da produção foi detectada mediante o estudo de 507 radiografias. Somando os casos suspeitos com os já reconhecidamente doentes, $a$ prevalência foi estimada pelos autores em 10,1\% (Amâncio et al., 1988; Bonciani, 1993). Trabalho simultâneo, realizado em outras empresas que processavam cimento-amianto, detectou condições ambientais de trabalho equivalentes, sem incluir, contudo, a avaliação radiológica, a qual, na opinião dos autores, mostraria níveis de prevalência de asbestose e de outras alterações pulmonares e/ou pleurais não muito distintos dos encontrados em três das nove empresas abordadas (Giannasi et al., 1988).

Durante o 5o Congresso de Pneumologia e Tisiologia do Rio de Janeiro, realizado em 1995, foi apresentado estudo de trabalhadores da in- dústria naval do Estado do Rio de Janeiro. Teriam sido encontrados 15 casos de asbestose entre os trabalhadores expostos (Ferreira, 1995).

Ainda em relação à asbestose, a experiência brasileira, relativamente sólida, pode também ser vista sob outro ângulo, ou seja, pelos casos enviados a ambulatórios especializados em doenças profissionais. Especificamente, no Ambulatório de Pneumopatias Ocupacionais da Fundacentro, em São Paulo, entre 1984 e 1994, a asbestose foi diagnosticada em 16 pacientes, entre 394 diagnosticados com pneumopatias ocupacionais. Todos os casos de $a s$ bestose vieram da indústria do amianto (fibrocimento e freios), mas os de doença pleural pelo asbesto (11 casos) tiveram procedências variadas (indústria do amianto, metalúrgicas, fundições, cerâmicas e vidro), sendo que muitos deles tinham dificuldade em lembrar-se da exposição ao asbesto, que não era a principal matéria-prima utilizada no ambiente de trabalho (Mendonça et al., 1994).

Em artigo de revisão sobre as doenças do aparelho respiratório associadas ao amianto está relatada a presença de quatro casos de asbestose, diagnosticados no Ambulatório de Doenças Ocupacionais da Fundação Oswaldo Cruz, no Rio de Janeiro (Castro \& Gomes, 1997).

Finalmente, mencionam-se os dados coletados por Giannasi, segundo a qual, a revisão da bibliografia brasileira mostrava "menos de uma centena de casos de doenças atribuídas ao amianto no Brasil neste século. São 56 casos de asbestose, dois de câncer de pulmão e quatro de mesotelioma, que foram apresentados em congressos ou em publicações médicas. A maioria destes não tiveram reconhecimento oficial" (Giannasi, 1996:58). Provavelmente, vários destes casos são os mesmos que foram apresentados ou publicados em distintos eventos ou publicações, e aqui já mencionados.

Quanto aos mesoteliomas de pleura - raros e graves tumores malignos que se dizia não ocorrerem em nosso meio -, acredita-se que o tempo de latência de 30, 35 ou mais anos, normalmente requerido de acordo com a experiência estrangeira, esteja se completando, e os casos de mesotelioma maligno comecem agora a aparecer. Sua raridade combinada com sua forte associação com a exposição ao asbesto transformaram-nos em doença maligna que sinaliza exposição ao asbesto e um forte indicador epidemiológico de exposição a estas fibras.

Nesta direção, a literatura científica brasileira, embora ainda extremamente escassa neste assunto, já traz o registro de três casos clínicos de mesotelioma maligno de pleura com associação etiológica a asbesto, detectados no 
Hospital das Clínicas da UNICAMP, pelo Prof. Eduardo Mello De Capitani e colaboradores. Os casos ocorreram na região de Campinas, São Paulo, em um período de dois anos, e foram detalhadamente investigados do ponto de vista clínico, laboratorial, anatomopatológico, além de por minuciosa investigação anamnésica ocupacional e ambiental. Um dos três casos havia sido exposto ao asbesto por período muito curto (cerca de um ano); outro, teve exposição doméstica durante sua infância a partir do asbesto trazido do ambiente de trabalho pelo pai; e o terceiro caso teve contaminação ocupacional indireta (De Capitani et al., 1997).

Concluindo esta seção dedicada ao estudo dos problemas causados pelo asbesto no Brasil, torna-se evidente, por um lado, que, apesar de uma série de limitações metodológicas e analíticas, a asbestose, enquanto doença profissional grave, está há cerca de 45 anos suficientemente documentada em nosso país, tanto a partir de estudos radiográficos em trabalhadores expostos, onde a prevalência média está ao redor dos $10 \%$, como em casuísticas de serviços de pneumologia. Por outro lado, a incidência de mesoteliomas de pleura apenas começa a despontar, com sérios indícios do crescimento epidêmico de sua incidência quando os diagnósticos incluírem, de modo correto, a anamnese ocupacional e ambiental, ao mesmo tempo em que o período de latência requerido por este tumor maligno for se completando, em função da evolução histórica do crescimento da exploração do asbesto, da industrialização do cimento-amianto e de outros usos do asbesto no Brasil.

Acredita-se que o câncer de pulmão relacionado ao asbesto está relativamente "escondido" ou "mascarado" por outros fatores de risco dada a sua inespecificidade clínica, radiológica e anatomopatológica, ainda que já existam evidências - não apenas epidemiológicas, mas também físicas - de seu nexo causal com o asbesto em nosso meio (Algranti et al., 1989; De Capitani, 1994; Wünsch Filho, 1995a, 1995b).

Percebe-se assim que todas as doenças descritas em outros países (asbestose, mesotelioma e câncer de pulmão etc.) estão registradas na literatura médica brasileira, algumas há quase cinqüenta anos.

\section{Debate sobre a nocividade do asbesto-crisotila}

Embora haja relativo consenso no que concerne às várias expressões da nocividade dos asbestos sobre a saúde humana, muito se tem discutido acerca da patogenicidade supostamente distinta das diferentes variedades de fibras de asbestos sejam as serpentinas (crisotila ou asbesto branco) sejam os anfibólios, isto é, a actinolita (asbesto marrom), a antofilita, a crocidolita (asbesto azul), a tremolita ou as misturas de fibras e seus contaminantes. Alguns pretendem demonstrar a relativa inocuidade da crisotila, em particular, no que se refere ao potencial carcinogênico, ou seja, à capacidade produzir câncer de pulmão e/ou mesoteliomas malignos (Wagner, 1986; McDonald et al., 1989, 1993, 1999; Case, 1991; Becklake, 1998; McDonald, 2000). Para Nicholson \& Raffn (1995:393), “o extenso e freqüentemente indigesto debate sobre a carcinogenicidade da crisotila é liderado primariamente pela indústria canadense do asbesto, sediada em Quebec, que mantém importantes mercados desta variedade de asbesto na América do Sul, na América Central e na África".

Alguns pesquisadores canadenses e britânicos vêm defendendo a tese de que a carcinogenicidade do asbesto-crisotila seria devida à "contaminação" da crisotila por fibras de anfibólios, em especial, fibras de tremolita (Wagner, 1986; McDonald et al., 1989; Case, 1991), tese que seria válida tanto para o mesotelioma maligno quanto para o câncer de pulmão, extensível também para o processo de fibrogênese (McDonald et al., 1999).

A "hipótese dos anfibólios" teria nascido da observação de que, em pulmões necropsiados, predominaria a retenção tecidual de anfibólios (crocidolita, amosita, tremolita, antofilita, actinolita etc.), quando comparado com a retenção de crisotila, o que levou à hipótese de que a nocividade e carcinogenicidade das fibras de asbestos seriam proporcionais e devidas ao grau de retenção no pulmão (McDonald et al., 1989; Mossman et al., 1990; Churg, 1991). No caso do Canadá, McDonald et al. (1980, 1989, 1993) entenderam que a tremolita seria provavelmente a fibra responsável pela maioria dos casos de mesotelioma na região mineira de Quebec (Liddell et al., 1997).

Na verdade, todas as análises de efeitos sobre a saúde causados pela crisotila são virtualmente complicadas pela contaminação dos principais minérios de crisotila com outras fibras minerais. Fibras de tremolita, actinolita ou antofilita podem contaminar o minério extraído das minas de Quebec; a tremolita contamina o minério de Chipre; a balangeroíta contamina os corpos minerais da Itália, e assim por diante. Nestes e em outros casos já estudados, o nível de contaminação tem sido inferior a 1\%, e as fibras de asbesto não-crisotila são extraídas dos minérios transportados a partir das 
respectivas minas. Esta contaminação prossegue após o processamento industrial. Contudo, "a análise dos diversos tipos de estudos sobre efeitos adversos sobre a saúde mostra fortemente que os efeitos da exposição à crisotila comercial são devidos à crisotila, e não a outras fibras eventualmente associadas" (Nicholson \& Raffn, 1995:408).

Em argumentação contrária à suposta inocuidade da crisotila, os autores citam dois tipos de achados. Em primeiro lugar, o estudo realizado em pacientes com placas pleurais (Churg, 1982), nos quais se observou que as fibras não-comerciais presentes nas placas são mais grossas e mais curtas que as de crocidolita comercial ou de outras fibras de anfibólios, sugerindo que as fibras que contaminam a crisotila podem ser menos carcinogênicas que os anfibólios comerciais. Em segundo, os autores citam o trabalho de Bégin et al. (1992), que identificaram 49 casos de mesotelioma de pleura em trabalhadores de mineração e de processamento industrial no Canadá, a partir dos registros do Seguro de Acidentes do Trabalho e Doenças Profissionais (Workman's Compensation Board). Vinte destes casos eram de trabalhadores da cidade que tem por nome "Asbestos”, Província de Quebec, e 29 casos eram originários das minas de Thetford, na mesma Província. A incidência de mesotelioma foi aproximadamente proporcional à quantidade de asbesto extraída ou processada em ambas as comunidades. Contudo, a razão das proporções de tremolita/crisotila no ar de ambas as comunidades mostrou que na comunidade de "Asbestos" ela tinha sido 7,5 vezes inferior à proporção tremolita/crisotila encontrada nas minas de Thetford. Assim, argumentam Nicholson \& Raffn (1995), se a etiologia de mesoteliomas estivesse vinculada ao teor de tremolita (e não ao de crisotila), seria de esperar que a incidência deste tumor maligno fosse muito mais baixa em "Asbestos" do que em Thetford.

Quanto ao câncer de pulmão, Nicholson \& Raffn (1995), após revisarem exaustivamente 13 estudos sobre mortalidade por tumor maligno, relacionando-a ao tipo predominante de fibra de asbesto presente na exposição ocupacional, os autores concluíram pela existência de uma relação de dose-dependência acumulada no tempo para a exposição a crisotila, tendo estimado o risco na faixa de 1,0 a $4,0 \%$ por fibra-ano/mL na indústria têxtil. Em outras atividades industriais, a estimativa não é muito distinta da de $1 \%$ por fibra-ano/mL.

Desse modo, a partir da análise destes 13 estudos de mortalidade, os autores demonstraram que o risco de câncer de pulmão é similar para a crisotila, amosita e crocidolita, quando analisado na perspectiva quantitativa do número de fibras presentes no ambiente de trabalho. Quanto ao mesotelioma, os autores concluíram, com base em 40 estudos que relacionam este tumor e o tipo predominante de fibra, que $a$ crisotila $e$ a amosita parecem produzir iguais riscos de ocorrência deste tumor. No caso da crocidolita, o risco seria de quatro a dez vezes o da crisotila (Nicholson \& Raffn, 1995). Por conseguinte, completam os autores, "estes estudos não permitiram estabelecer um Limite Permitido de Exposição que assegure a inexistência de risco decorrente da exposição ocupacional a qualquer tipo de fibra de asbesto" (Nicholson \& Raffn, 1995:408).

Na mesma linha está o estudo realizado por Stayner et al. (1997) em coortes de trabalhadores expostos a crisotila nos Estados Unidos, quando conclui que "foi absolutamente impossível determinar um limite de tolerância para os modelos matemáticos desenvolvidos para interpretar as relações exposição-resposta, tanto para o câncer de pulmão, quanto para a asbestose. Somente se conseguiu um limite de exposição segura, na concentração zero. Portanto, nossas análises não conseguem dar suporte aos argumentos a favor de um limite seguro para a exposição à crisotila, quer em termos de câncer de pulmão, quer em termos de asbestose" (Stayner et al., 1997:651) (Grifo nosso).

Com efeito, um dos mais elevados riscos de adquirir câncer de pulmão relacionado com o asbesto-crisotila foi observado e estudado em trabalhadores de produção de tecidos de asbesto, na Carolina do Sul, nos Estados Unidos, onde a fibra de asbesto utilizada era inteiramente crisotila (Dement, 1991; Dement \& Brown, 1993; Dement et al., 1994; Stayner et al., 1997).

Aliás, esta coorte de trabalhadores da indústria têxtil de asbesto-crisotila, na Carolina do Sul, Estados Unidos, também conhecida como "coorte do NIOSH", constitui-se - juntamente com a coorte dos trabalhadores da mineração e processamento de Quebec, no Canadá - em uma das mais completas e longas coortes de ex-expostos à crisotila, de onde muitos trabalhos científicos sobre a nocividade desta variedade de amianto têm saído (Dement, 1991; Dement \& Brown, 1993; Dement et al., 1994; Stayner et al., 1997). Historicamente, as fibras de crisotila para esta fiação/tecelagem de asbesto-crisotila na Carolina do Sul eram importadas do Canadá (Quebec e British Columbia) e do Zimbábue.

Outrossim, revisando a patogenicidade do asbesto-crisotila, principalmente no que se refere ao risco de câncer de pulmão, Stayner et al. 
(1996), do Instituto Nacional de Saúde e Segurança Ocupacional (NIOSH), dos Estados Unidos, são enfáticos ao afirmarem que “...estudos toxicológicos e epidemiológicos fornecem fortes evidências de que a crisotila está associada com um risco aumentado de câncer de pulmão e de mesotelioma. Para induzir os mesoteliomas, a crisotila poderia ser menos potente que determinados anfibólios, mas existem pouquíssimas evidências indicando risco de indução de câncer pulmonar mais baixo [do que o dos anfibólios]” (Stayner et al., 1996:184).

Por conseguinte, não seria correto associar a etiologia dos efeitos malignos do asbesto, ao tipo de fibra retida no tecido pulmonar - fundamento da "hipótese dos anfibólios", que leva a inocentar a crisotila. Como explicam Nicholson \& Landrigan (1994), da Mount Sinai School of Medicine, em Nova York, a aerodinâmica e o comportamento das fibras de crisotila no interior do aparelho respiratório diferem por seu comprimento e formato do que ocorre com anfibólios, fato que explicaria a diferença entre sua presença no pulmão e sua verdadeira nocividade e carcinogenicidade, amplamente confirmadas em estudos experimentais (Frank, 1995a; Smith \&Wright, 1996; Frank et al., 1998). Aliás, já se demonstrou que a fragmentação completa de uma fibra de crisotila é capaz de formar mais de mil fibrilas extremamente finas, invisíveis à microscopia eletrônica de tecido pulmonar (Wagner et al., 1973).

Na verdade, como há estudos que demonstram, em casos de mesotelioma de pleura, a presença exclusiva de fibras de crisotila no tecido pulmonar (e não de outras fibras), a maior parte dos autores tende atualmente a concluir ser incorreto tentar correlacionar a etiologia do tumor com o conteúdo e a natureza das fibras detectadas no pulmão por ocasião da necropsia. Cabe lembrar que os estudos de microscopia de fibras de asbesto no tecido pulmonar incluem apenas as fibras maiores de $5 \mathrm{~mm}$ de comprimento, subestimando ou excluindo deste tipo de análise as fibras e as fibrilas de crisotila, sabidamente mais curtas. Por sua vez, o mecanismo fisiopatogênico da ação carcinogênica, sobretudo com carcinógenos de longa latência, desenvolve-se independentemente da retenção das fibras no tecido pulmonar durante o período de tempo que permeia entre sua inalação e o momento da necropsia. A eventual correlação, na verdade, dar-se-ia mais corretamente com o número de fibras e fibrilas de $\mathrm{cri}$ sotila retidas na pleura parietal (e não no tecido pulmonar) e que são de difícil visualização por seu pequeno tamanho (Dement, 1991; Smith \& Wright, 1996).
Cabe destacar que muitos trabalhos científicos recentes confirmam a carcinogenicidade das fibras de crisotila, mesmo puras e não contaminadas com outras fibras de anfibólios, demonstrada pela produção de mesoteliomas malignos de pleura (Mancuso, 1988; Harington, 1991; Huncharek, 1994; Nicholson \& Landrigan, 1994; Nicholson \& Raffn, 1995; Smith \& Wright, 1996; Frank et al., 1998).

Nos Estados Unidos, por exemplo, as análises de mortalidade de trabalhadores de isolantes térmicos que foram expostos unicamente a crisotila antes de 1937 e a crisotila e amosita a partir de então, indicam que a crisotila tem potencial para produzir mesotelioma similar ao da amosita (Lemen, 1995; Nicholson \& Raffn, 1995; Nicholson, 2000).

Outro estudo com base na razão entre $m e$ soteliomas e cânceres do pulmão realizado naquele país, envolvendo 38 estudos disponíveis na literatura científica e em outros informes, indicou que a potência da crocidolita para a produção de mesotelioma é 2 a 4 vezes a potência da amosita ou da crisotila e que ambas têm potências carcinogênicas de produzir mesotelioma similares (U. S. Environmental Protection Agency, 1986 apud Nicholson, 2000).

Entre os muitos estudos que confirmam a carcinogenicidade da crisotila, per se, pode ser citada a casuística italiana de mesoteliomas de pleura ocorridos em trabalhadores ferroviários e em trabalhadores de refinarias de açúcar expostos predominantemente ao asbesto-crisotila (Maltoni et al., 1991, 1995a, 1995b).

Outrossim, estudos epidemiológicos desenvolvidos com uma coorte de trabalhadores da maior fábrica de cimento-amianto da Itália, em Casale Monferrato, onde operou de 1907 a 1986, confirmam também os achados de malignidade - tanto câncer de pulmão quanto mesotelioma de pleura e de peritônio - associados à exposição ocupacional predominantemente à crisotila (Magnani et al., 1996). Aliás, segundo Addison (1999), as minas italianas de Balangero eram consideradas produtoras de crisotila "pura", sem qualquer contaminação por tremolita ou, no máximo, muito escassa.

Observações de mesma natureza foram registradas no Zimbábue, onde se diz serem as fibras de asbesto-crisotila extremamente "puras", isto é, não contaminadas por anfibólios. No entanto, os autores - contrariando a cultura prevalente nas empresas e defendidas por seus médicos - foram capazes de encontrar, por meio de estratégias de busca ativa de casos, dezenas de casos "novos" de asbestose, de placas pleurais e outras manifestações de doença pleural, de câncer de pulmão e de mesotelioma de pleura em 
trabalhadores expostos exclusivamente à crisotila dita doméstica (Cullem \& Baloyi, 1991).

Diz-se também que as fibras de crisotila extraídas na China são igualmente "puras", isto é, não contaminadas com anfibólios, o que explicaria a existência "tão somente" de asbestose e câncer pulmonar, ao lado de uma extrema raridade de casos de mesotelioma de pleura (Hillerdal, 1999).

Mesmo no Canadá (Província de Quebec), onde a "hipótese dos anfibólios" foi desenvolvida e ainda vem sendo defendida por alguns, investigação realizada com trabalhadores da indústria, de isolantes térmicos, de construção de navios e da construção civil - cuja exposição primária deveu-se predominantemente à crisotila, e os anfibólios tiveram importância secundária - detectou e analisou, de modo criterioso, mais de setenta casos de mesotelioma maligno de pleura (Bégin et al., 1992).

Aliás, os estudos pioneiros realizados por McDonald \& McDonald (1980) já mostravam casos de mesotelioma de pleura em crianças, filhos de mineradores de crisotila. Do mesmo modo, Sanden et al. (1992), revisando extensas casuísticas de mesotelioma de pleura, identificaram oito casos deste tumor maligno associados à exposição à poeira de asbesto-crisotila ocorrida no ambiente domiciliar. Com efeito, após citarem esses trabalhos - entre muitos outros - Smith \& Wright, pesquisadores da Escola de Saúde Pública da Universidade da Califórnia em Berkeley, não tiveram dúvida em concluir que "os dados acima demonstram que a exposição a crisotila, mesmo em niveis relativamente baixos para os esperados no interior de domicílios, pode causar mesotelioma maligno" (Smith \&Wright, 1996:261)

A propósito, estes autores - após revisarem mais de cem trabalhos científicos e analisarem, de modo detalhado e crítico, 25 estudos epidemiológicos de coortes, que enfocam a ocorrência destes tumores malignos e sua associação com exposição ao asbesto - foram extremamente enfáticos ao concluírem que:"(1) o asbesto-crisotila é uma potente causa de mesotelioma pleural; (2) a imensa maioria dos mesoteliomas é atribuível à exposição ao asbesto; $e$ (3) as fibras de asbesto-crisotila têm sido as fibras predominantemente utilizadas. Baseados nesta evidência, concluímos que o asbesto crisotila é de longe o mais importante contribuidor para a etiologia dos mesoteliomas pleurais nos Estados Unidos e em outros países onde a crisotila é a fibra de uso predominante" (Smith \&Wright, 1996:262) (Grifo nosso).

Por outras palavras, eis as dos pesquisadores do NIOSH, dos Estados Unidos: “dadas as evidências de um significante risco de câncer de pulmão, a falta de evidências conclusivas a favor da 'hipótese dos anfibólios', e o fato de que trabalhadores estão geralmente expostos a uma mistura de fibras, concluímos que é prudente tratar a crisotila, virtualmente com a mesma preocupação como se fossem asbestos na forma de anfibólios” (Stayner et al., 1996:184) (Grifo nosso).

Consistentemente, a comissão internacional de especialistas reunidos pelo Programa Internacional de Segurança das Substâncias Químicas (IPCS), após revisar exaustivamente a literatura internacional, e discutir largamente com representantes da comunidade científica internacional, concluiu que " $a$ exposição ao asbesto crisotila acarreta riscos aumentados para a asbestose, câncer do pulmão e mesotelioma, de maneira dose-dependente. Não foram identificados limites permitidos de exposição para os riscos de carcinogênese" (IPCS, 1998:144).

Conclui-se que, com tantas evidências idôneas de natureza experimental, anatomopatológica e, principalmente, de natureza epidemiológica demonstradas ao longo de tanto tempo e em tantos lugares diferentes, e por tantos diferentes pesquisadores e estudiosos, não sobrevivem os argumentos em defesa da inocuidade do asbesto-crisotila.

Pelo contrário, esta fibra mineral "pura" ou "contaminada" - canadense, russa, chinesa, italiana ou brasileira -, tal como seus anfibóliosirmãos, causa igualmente asbestose, câncer de pulmão, mesotelioma de pleura ou de peritônio, afora outras tantas doenças. Trata-se de substância química cancerígena confirmada no ser humano de forma ampla e desnecessariamente redundante.

\section{Respostas da comunidade internacional ao problema da nocividade do asbesto e a mobilização pelo seu banimento}

Conforme levantamento realizado recentemente, o asbesto já havia sido banido nos seguintes países (dispostos em ordem alfabética): Alemanha, Arábia Saudita, Áustria, Bélgica, Dinamarca, Finlândia, França, Holanda, Inglaterra, Itália, Noruega, Nova Zelândia, Polônia, República Checa, Suécia e Suíça (Giannasi, 1988; Collegium Ramazzini, 1999a, 1999b; Lemen, 2000). Na Europa, a Holanda, a Suécia, a Noruega e a Dinamarca foram os primeiros países a implementar o banimento total do asbesto. Na década de 90, a mesma decisão foi tomada pela Alemanha, Finlândia e, mais recentemente, pela França (Karjalainen, 1997). 
Na Suécia, as primeiras regulamentações sobre a utilização do asbesto são de 1964, tendo sido, desde então, seguidas por uma série de normas e recomendações que incluíram o banimento completo da crocidolita, em 1976; o banimento quase completo - com poucas exceções - de todas as formas de asbesto, em 1986; a proibição do uso de lonas e pastilhas de freios em automóveis e motocicletas novos, a partir de 1o de janeiro de 1987, e a comercialização de automóveis usados, com freios contendo asbesto, a partir de 1o de julho de 1988. As poucas exceções que ainda eram temporariamente permitidas na Norma Sueca de 1986 (National Swedish Board of Occupational Safety and Health, Ordinance AFS 1986:2, concerning Asbestos, de 23 de janeiro de 1986) estavam sujeitas a estrito controle fiscalizatório e dependiam de permissão prévia do Conselho Nacional Sueco de Saúde e Segurança Ocupacional (Peters \& Peters, 1988).

Nos Estados Unidos, as medidas para assegurar a redução da exposição e, depois, a proibição progressiva do asbesto (phase out) têm tido longa trajetória, tanto por meio da agência governamental federal que trata das questões de Saúde e Segurança no Trabalho (Administração de Saúde e Segurança Ocupacional OSHA), como pela agência governamental federal que trata da questões de proteção ambiental (Agência de Proteção Ambiental - EPA).

Assim, a OSHA, órgão do Departamento do Trabalho (DOL), criado em 1970, baixou o limite permitido de exposição (PEL) de 5 fibras $/ \mathrm{cm}^{3}$ de ar, para 2 fibras $/ \mathrm{cm}^{3}$ de ar em 1976; o PEL da OSHA foi reduzido em 10 vezes, em 1986, sendo definido em 0,2 fibra $/ \mathrm{cm}^{3}$ de ar; em 1994, o PEL foi novamente reduzido à metade do valor anterior, isto é, a $0,1 \mathrm{fibra} / \mathrm{cm}^{3}$ de ar (TWA ou Valor Médio Ponderado no Tempo, para 8 horas), com a observação de "risco de câncer" e com um valor teto para 30 minutos de 1,0 fi$\mathrm{bra} / \mathrm{cm}^{3}$ (U. S. Department of Labor, 1994).

Cabe lembrar que o valor de $0,1 \mathrm{fibra} / \mathrm{cm}^{3}$ de ar já era o Limite Recomendado de Exposição Definido por Razões de Saúde (REL), estabelecido pelo NIOSH e também o Limite de Tolerância (TLV), estabelecido pela Conferência Americana de Higienistas Industriais Governamentais (ACGIH), a qual agrega ao valor do TLV a observação de "carcinogênico humano confirmado” (ACGIH, 1999).

Por sua vez, a EPA daquele país vem, desde o início da década de 80, batalhando pelo banimento do asbesto nos Estados Unidos, com base em estudos epidemiológicos a respeito da extrema nocividade dessa fibra que foram considerados suficientemente convincentes (U. S. Department of Labor, 1986; Percival et al., 1996).
Assim, em 1989, com base na Lei de Controle das Substâncias Tóxicas (TSCA), a EPA estabeleceu a proibição total, em etapas sucessivas, da produção, importação, processamento e comercialização de quase todos os produtos contendo asbesto, o que significaria uma redução de $94 \%$ do consumo de asbesto nos Estados Unidos, segundo a própria estimativa da EPA. O banimento do asbesto foi vinculado ao que a EPA chamou de "risco injustificado para a saúde humana e para o meio ambiente" (U. S. Department of Labor, 1986:22780).

A decisão da EPA de estabelecer o banimento do asbesto em seu ciclo completo de vida foi baseada nos seguintes argumentos:

- A importância e a gravidade dos efeitos sobre a saúde humana, refletida em mortes precoces e dolorosas devidas a mesotelioma de pleura, câncer de pulmão, câncer gastrointestinal e outros cânceres, assim como a asbestose e outras doenças: "estudos mostram que o asbesto é um carcinógeno altamente potente e que efeitos muito graves sobre a saúde humana podem ocorrer após exposições, mesmo de curta duração, mas de elevado nível de concentração, ou após longo tempo em concentrações baixas. A exposição ao asbesto é compatível com um modelo linear de dose-resposta para câncer de pulmão, sem um limite seguro de exposição" (Percival et al., 1996:571).

- Ubiqüidade da exposição: “As pessoas estão freqüentemente expostas ao asbesto sem o saber e raramente estão em posição de se protegerem a si próprias. As fibras de asbesto geralmente são invisíveis, sem odor, muito duráveis ou persistentes, e altamente aerodinâmicas. As fibras podem se deslocar por grandes distâncias e permanecem no meio ambiente por tempo muito longo. Portanto, a exposição pode ocorrer muito tempo após a liberação da fibra de asbesto, e em local muito distante da fonte de liberação" (Percival et al., 1996:572).

- Aumento da carga poluidora e dos expostos: "adições ao atual estoque de produtos contendo asbesto teriam contribuído para aumentar a carga de asbesto no meio ambiente. Isto acarretaria um possível aumento do risco da população geral (...) e um risco para as gerações futuras, tendo em vista a longa longevidade do asbesto" (Percival et al., 1996:572).

- Número de pessoas expostas no ciclo de vida das fibras: "as atividades que podem produzir a liberação de fibras de asbesto em seu longo ciclo de vida incluem a mineração, o processamento de fibras em produtos industrializados, o transporte, a instalação, o uso, a manutenção, a reparação, a retirada, e a disposição final dos produtos contendo asbesto" (Percival et al., 572). 
A EPA estimou o número potencial de expostos ocupacionalmente (alguns milhares, nos Estados Unidos) e, através de estudos de modelagem, estimou os milhões de pessoas da população geral que acabam se expondo no ciclo completo de vida a estas fibras.

- A liberação das fibras, a partir de produtos que as contêm: mesmo respeitando os limites permitidos de exposição estabelecidos pela OSHA (à época, 0,2 fibra/ $\mathrm{cm}^{3}$ de ar), a EPA entendia que muitos milhares de trabalhadores expostos não estariam cobertos pelas normas da OSHA no que se refere às medidas de engenharia requeridas e à proteção individual. Assim, "o fato de os asbestos serem potentes cancerígenos, picos de exposição episódica incontrolada acarretam significativo risco" (U. S. Department of Labor, 1986:22782).

- A existência de pessoas desprotegidas contra os riscos do asbesto em seu ciclo de vida completo e que estão fora da jurisdição de agências como a OSHA e de outras medidas de controle já existentes.

- A utilização contínua do asbesto no mercado norte-americano apesar da existência de outros produtos alternativos seguros ou de risco mais baixo, que não têm sido utilizados: "As evidências apoiam a conclusão de que substitutos do asbesto já existem ou estarão logo disponíveis, para todos os usos do asbesto. Ao escalonar o banimento do asbesto, a EPA levou em conta a disponibilidade de substitutos que não contêm asbesto (...) adiando o banimento para umas poucas utilizações, muito específicas e limitadas, que ainda dependem destes produtos" (Percival et al., 1996:573).

- Estimativas de mortes evitáveis que poderão resultar do banimento completo do asbesto (a EPA estimou estes números, para o caso de mortes por câncer).

- Insuficiência ou inadequação de outras medidas que não o banimento completo, escalonado: "outras opções de controle ou falham em importantes fases do ciclo de vida do asbesto ou dos produtos que o contêm, ou são injustificadamente onerosas. A EPA conclui, portanto, que as ações tomadas com o ato da proibição total constituem os meios menos onerosos de reduzir os riscos devidos ao asbesto, em seu ciclo de vida completo" (Percival et al., 1996:574).

A indústria norte-americana do asbesto entrou com ação judicial contra a EPA, em 1991, questionando vários dos argumentos acima listados. A Corte julgou procedente a argumentação empresarial da época, o que levou à suspensão temporária do ato de proibição, que foi posteriormente substituído por outros atos de banimento setorial.
Na Finlândia - que já foi o maior produtor e exportador de asbesto-antofilita do mundo-, a mineração desta fibra foi desativada em 1975, enquanto a industrialização de fibras de amianto foi desativada em 1988. A produção, venda, importação e uso de asbesto e de produtos que o contêm foi proibida a partir de 1o de janeiro de 1993, por decisão do Conselho de Estado daquele país, com poucas exceções relacionadas às operações de demolição de obras e desmantelamento de instalações (Huuskonen et al., 1995; Karjalainen et al., 1997).

Tanto na Finlândia como na Suécia, o atual número de mortes prematuras causadas por mesotelioma de pleura relacionado ao asbesto já é superior ao número de acidentes do trabalho fatais no mesmo período de tempo, estimando-se que a epidemia atinja seu pico por volta do ano 2010 (Jarvholm et al., 1990; Englund, 1995; Huuskonen et al., 1995).

Na França, o banimento completo de todas as formas de asbesto foi anunciado pelo governo em 3 de julho de 1996, tornando-se efetivo a partir de 1o de janeiro de 1997 (Asbestos Institute, 1997). A decisão política do governo francês de proibir a importação e venda de produtos que contêm asbesto, incluindo cimentoamianto, deu-se logo após a divulgação do estudo elaborado por um grupo de pesquisadores convidados pelo Instituto Nacional de Saúde e Pesquisa Médica (INSERM), a pedido da Direção de Relações de Trabalho (Ministério do Trabalho) e da Direção Geral de Saúde (Ministério de Assuntos Sociais), do governo francês. O estudo foi desenvolvido de agosto de 1995 a maio de 1996, e divulgado em junho de 1996, na forma de um Relatório, de mais de quinhentas páginas, intitulado "Effects sur la Santé des Principaux Types d'Exposition a l'Amiante" (INSERM, 1997). Pela gravidade dos dados analisados e das estimativas de dano futuro, o banimento de todas as formas de asbesto constituiu a alternativa técnica recomendada pelos pesquisadores, e, em seguida, adotada pelo governo.

Na verdade, o movimento contra o amianto naquele país tem longa trajetória, em que o movimento social atuou marcantemente. Avanços legais já haviam ocorrido no mesmo ano de 1996, como, por exemplo, os Decretos 96-97 e 96-98, referentes à proteção da população geral e dos trabalhadores contra o amianto, primeiro, em prédios e edificações (Decreto 9697) e, em seguida, em ambientes de trabalho (Decreto 96-98), quando, entre outras medidas, passou a ser adotado o valor de $0,1 \mathrm{fibra} / \mathrm{cm}^{3}$ de ar, como Limite de Tolerância para a crisotila (France, 1996). 
Antes, contudo, as denúncias na mídia, ocorridas em julho de 1994, sobre a ocorrência de casos de câncer de pulmão em professores e em trabalhadores que haviam trabalhado em prédios contendo material isolante à base de asbesto, haviam mobilizado a opinião pública. Em outubro de 1994, a constatação da presença de asbesto em materiais para isolamento nos prédios da Universidade Jussieu mobilizou segmentos acadêmicos, estudantis e sindicais, ocasião em que foi criado, naquela Universidade, o "Comitê Anti-Asbesto". Em abril de 1995, o Comitê organizou um evento intitulado "Asbesto: Um Problema de Saúde Pública”. Em junho de 1995, a revista Sciences et Avenir denuncia a presença de asbesto em prédios, associando-o ao que denominou "epidemia mortal”, ao mesmo tempo em que acusava o governo francês por omissão. Com base nesta matéria, a televisão apresentou um programa intitulado "asbesto mortal", que provocou grande consternação no país. Em outubro de 1995, anunciaram-se novos aperfeiçoamentos na legislação referente ao asbesto. Em fevereiro de 1996, foi criada a "Associação das Vítimas do Amianto" (ANDEVA) que, entre muitas outras atividades, acionou judicialmente funcionários e dirigentes do governo francês, a Indústria do amianto, assim como médicos e cientistas que se opunham à eliminação das fibras nocivas, inclusive da Academia Nacional de Medicina, que em maio do mesmo ano, se pronunciara de forma conservadora (Asbestos Institute, 1997).

Não é difícil imaginar a reação de países produtores e exportadores de crisotila, liderados pelo Canadá, traduzida por intenso trabalho junto a cientistas e fóruns científicos, bem como junto a fóruns do comércio bilateral (França-Canadá) e do comércio internacional (a Organização Mundial do Comércio - OMC -, por exemplo), onde não faltaram ameaças de retaliação violenta decorrentes da perda substancial de mercados exportadores. Outros países europeus já haviam proibido a importação e, mais recentemente, a União Européia posicionou-se do mesmo modo. Para os defensores do amianto, o Informe do INSERM e a imediata decisão pelo banimento total não teriam levado em consideração as diferenças que existem entre os distintos tipos de fibra de asbesto, teriam deixado de incluir os estudos que mostram ausência de efeitos em trabalhadores expostos exclusivamente à crisotila e, por último, teriam subestimado os riscos à saúde causados pelos substitutos do asbesto (Asbestos Institute, 1997).

Na União Européia, a recente Diretiva da Comissão das Comunidades Européias 1999/
77 /EC, datada em 26 de julho de 1999, proibiu a venda e a utilização de certas fibras de amianto ainda autorizadas, notadamente a do tipo crisotila. A decisão, aplaudida pelos adversários do amianto na Europa, facilitará a aplicação do chamado "princípio de precaução", tendo em vista os estudos epidemiológicos que estimam em cerca de 250 mil o número de futuras vítimas de mesotelioma de pleura. Segundo o artigo 2o da nova Diretiva da Comissão das Comunidades Européias, os Estados Membros europeus deverão adotar esse novo texto a partir de 1o de janeiro de 2005 (Commission of the European Communities, 1999; O Estado de São Paulo, 1999).

A Comissão levou em conta a necessidade de um período de ajustamento para eliminar a venda e a utilização do amianto crisotila e dos demais produtos que contêm esse tipo de mineral, fixando a data de 1o de janeiro de 2005 como limite máximo para entrar em vigor o banimento completo em todos os países da União Européia. Já a partir da entrada em vigor desta Diretiva, os países não podem mais autorizar a introdução de novas aplicações do amianto crisotila em seus territórios. A Comissão lembra a existência, hoje, de produtos de substituição que não são considerados cancerígenos, oferecendo risco muito menor (Commission of the European Communities, 1999; O Estado de São Paulo, 1999).

Na África do Sul, a exportação de amosita havia cessado totalmente em 1993, assim como a de crocidolita havia caído a cerca de $5 \%$ do que se exportava em 1970. A partir de 1996, a produção de crisotila também sofreu forte queda, caindo a $37 \%$ de sua produção habitual, com previsão de encerramento total da exportação de crisotila em poucos anos. Como dizem os autores, "finalmente, após 40 anos do estabelecimento da associação entre exposição a crocidolita e mesotelioma, na África do Sul (Wagner et al., 1960), toda a comercialização desta fibra chega a um fim" (Harington \& McGlashan, 1998 apud Harington \& McGlashan, 2000:229)

Na Austrália, a empresa de extração e exportação de crocidolita, instalada em 1937, foi encerrada em 1966, após haver produzido milhares de casos de mesotelioma, considerado como "a modern industrial disaster" (Musk et al., 1992).

No entanto, tal como ocorre com outros produtos tóxicos ou perigosos proibidos ou banidos nos países mais desenvolvidos (Castleman, 1995), com o fechamento dos mercados de importação das fibras de asbesto dos países mais industrializados, vem se acentuando a 
tendência de deslocamento do eixo do comércio internacional na direção dos assim chamados "países em desenvolvimento", ou "países do terceiro mundo", onde vem-se dando o consumo destas fibras nocivas, principalmente em produtos de cimento-amianto (Levy \& Seplow, 1992; Frank, 1993; Lemen \& Bingham, 1994; Chen \& Huang, 1997; Giannasi \& ThébaudMony, 1997; Karjalainen, 1997; Ladou, 1999; Castleman, 2000).

Por este motivo, o movimento internacional pela defesa da vida e da saúde, no que concerne aos efeitos nocivos das fibras de asbesto sobre a saúde humana, vem convocando cientistas e profissionais de saúde e de áreas correlatas - além de políticos e tomadores de decisão - para um esforço universal na direção do banimento deste produto.

Com este propósito, o Collegium Ramazzi$n i$, por exemplo, entidade acadêmica internacional sediada em Bolonha, na Itália, que reúne cerca de 180 cientistas de trinta distintos países, por decisão tomada na reunião anual de seus membros, realizada em Carpi, na Itália, em 24 de outubro de 1998, vem publicando, nas principais revistas científicas de Saúde \& Trabalho no mundo, uma mensagem de convite ou convocatória para uma ação internacional coordenada, intitulada "Call for an International Ban on Asbestos" (convocatória, chamada, por um banimento internacional do asbesto) (Collegium Ramazzini, 1999a, 1999b; Maltoni, 1999).

A convocatória do Collegium Ramazzini provocou e vem provocando, na forma de "cartas ao editor" das revistas científicas que a publicaram, uma série de manifestações de apoio e aplauso emitidas por vários cientistas e profissionais que defendem a proibição total do asbesto-crisotila (banimento) (Castleman, 2000; Greenberg, 2000; Lemen, 2000; Maltoni, 2000), ao lado da reação de outros, que continuam a defender a inocuidade da crisotila e a suposta eficácia de seu "uso controlado" (McDonald, 2000).

\section{Inadequação do atual posicionamento brasileiro sobre o problema e a necessidade de sua revisão urgente}

No Brasil, apesar de alguns avanços no tratamento da questão do asbesto ocorridos nos últimos vinte anos - como se verá adiante - a opção pela tese do "uso seguro" do amianto consolidou, de certa forma, não apenas uma posição política e tecnologicamente insustentável nos médio e longo prazos, como acabou colo- cando o país numa posição de explícita defesa da crisotila, na contramão da História, e para prejuízo da saúde, da vida e do meio ambiente.

Na verdade, o conjunto de medidas legais direcionadas ao manejo da questão do asbesto (amianto) no Brasil, apesar de estas terem sido adotadas há pouco tempo - na década de 90 -, já estava superado, de certa forma, posto que teve instrumentos internacionais da Organização Internacional do Trabalho (OIT) concebidos no início da década de 80 como paradigma, os quais, por sua vez, também nasceram antigos e enviesados na sua forma de lidar com questões da complexidade do asbesto (amianto) (Giannasi \& Thébaud-Mony, 1994, 1997; Thébaud-Mony, 1995).

O conjunto de medidas legais ou normativas adotadas pelo Brasil, disposto em ordem cronológica, pode ser assim resumido:

- Resolução no 7 do Conama (Conselho Nacional do Meio Ambiente), que regulamenta a rotulagem do asbesto e produtos que o contêm, de 16 de setembro de 1987 (Atlas, 1999);

- Decreto Executivo no 126, que promulga a Convenção no 162, da OIT, sobre a "utilização do asbesto em condições de segurança”, 22 de maio de 1991 (Brasil, 1991);

- Portaria no 1, do Departamento de Segurança e Saúde do Trabalhador, do Ministério do Trabalho e Previdência Social, que alterou o Anexo 12 da Norma Regulamentadora (NR) no 15, estabelecendo "limites de tolerância para poeiras minerais - asbestos”, 28 de maio de 1991 (Atlas, 1999);

- Lei no 9.055, que "disciplina extração, industrialização, utilização, comercialização e transporte do asbesto/amianto e dos produtos que o contenham, bem como das fibras naturais ou artificiais, de qualquer origem, utilizadas para o mesmo fim e dá outras providências.", 1o de junho de 1995 (Atlas, 1999);

- Decreto no 2.350, que "regulamenta a Lei no 9.055, de 1o de junho de 1995, e dá outras providências" 15 de outubro de 1997 (Atlas, 1999).

O estudo exaustivo e crítico deste arcabouço legal e de seus antecedentes poderia confirmar as observações relativas a seu obsoletismo nato e ao viés ideológico que permeia estes diplomas. Não sendo esta a finalidade precípua deste trabalho, serão apenas listados alguns exemplos e aspectos relacionados com a gênese destes instrumentos.

Assim, por exemplo, no que se refere à informação ao público em geral e aos trabalhadores acerca da natureza e gravidade dos riscos do amianto, a Resolução no 7 do Conselho Nacional do Meio Ambiente (Conama), de 16 de setembro de 1987, que regulamentou a ro- 
tulagem deste produtos cancerígenos, estabeleceu os seguintes dizeres: "Cuidado! Este produto contém fibras de amianto. Evite a geração de poeira. Respirar poeira de amianto pode prejudicar gravemente sua saúde. O perigo maior é para os fumantes" (Teixeira et al., 1988; Atlas, 1999).

Por sua vez, a Portaria no 1 do Ministério do Trabalho estabeleceu a obrigatoriedade da rotulagem com os seguintes dizeres: "Atenção: contém amianto. Respirar poeira de amianto é prejudicial à saúde. Evite risco: Siga as instruções de uso" (Atlas, 1999).

Como visto anteriormente, o potencial carcinogênico do asbesto já era conhecido e comprovado há mais de 25 anos, de sorte que rotulá-lo do modo como ambas as normas oficiais o fizeram foi, no mínimo, leviano. Os termos que haviam sido propostos ao Ministério do Trabalho incluíam no rótulo a advertência: "Risco de câncer e doença pulmonar se inalado" (Teixeira et al., 1988). Na Portaria no 1, de 1991, o risco de câncer e de doença pulmonar desapareceu; aliás, foi transferido para o leitor do rótulo: "Evite risco" (Atlas, 1999).

O segundo exemplo diz respeito aos "limites de tolerância" estabelecidos pelo Ministério do Trabalho, no cumprimento do Art. 200 da Consolidação das Leis do Trabalho (CLT). Entre outras providências de indicação óbvia, a Portaria no 1 reduziu à metade o então "limite de tolerância” para fibras respiráveis de asbestocrisotila, isto é, de 4,0 para 2,0 fibras $/ \mathrm{cm}^{3}, v a$ lor que nascia completamente obsoleto, posto que dez vezes superior ao então utilizado em outros países e 20 vezes superior ao valor já então recomendado por razões de saúde (Atlas, 1999).

Muitos exemplos poderiam ser mencionados aqui e merecem ser estudados em outro momento.

O que chama a atenção, na verdade, é que tanto a Resolução no 7 do Conama, de 1987, como a Portaria no 1, de 1991, expressavam a intenção brasileira de tomar a Convenção no 162 da OIT, que trata da "utilização do asbesto em condições de segurança”, com sua correspondente Recomendação no 172, ambas de 1986, como escudo e paradigma para um posicionamento político e técnico que, na esteira de uma suposta proteção da saúde e segurança dos trabalhadores, preservasse o espaço da crisotila no Brasil.

Nessa direção, o Seminário Nacional sobre Exposição Ocupacional ao Asbesto, promovido pelo Comitê de Estudos do Amianto (CEA), com o apoio da Secretaria de Segurança e Medicina do Trabalho do Ministério do Trabalho, Fundacentro, CNTI, CNI, SESI/DN e ABRA, realizado em Brasília, Distrito Federal, no mês de julho de 1986, fez parte dessa mobilização em prol da imediata adoção da Convenção no 162 da OIT pelo Brasil, como pode ser visto pelo teor das Conclusões e Recomendações desse evento.

Com efeito, a ratificação brasileira da Convenção no 162 foi depositada na OIT em 18 de maio de 1990 e promulgada em 22 de maio de 1991, através do Decreto Executivo no 126, publicado no Diário Oficial da União, de 23/5/91. A Portaria no 1, datada de 28/5/91, foi justificada pela "necessidade de se regulamentar a Convenção no 162, da Organização Internacional do Trabalho que trata da 'utilização do asbesto em condições de segurança'- 1986” (Scliar, 1998; Atlas, 1999).

A ênfase que se dá, nesta seção, à questão da Convenção no 162 da OIT, tal como a sua ratificação pelo Brasil, pareceria sem sentido e, mesmo, contraproducente, se não existissem tantas evidências sobre a forte influência de lobbies de países produtores e exportadores de asbesto-crisotila, liderados pelo Canadá e apoiados pelo Brasil, no longo processo de elaboração interna e discussão dos textos da Convenção e da Recomendação, até sua adoção pela Conferência Internacional do Trabalho, em junho de 1986. De uma única vez, e em âmbito internacional, alcançava-se a dupla façanha de proibir a extração, exportação, industrialização e utilização dos asbestos-anfibólios (amosita, crocidolita, tremolita, antofilita, etc.), já então banidos ou abandonados na maioria dos países, ao mesmo tempo em que se protegia a $\mathrm{cri}$ sotila, atribuindo-lhe suposta inocuidade de efeitos deletérios à saúde e à vida, quando utilizada em condições ditas "seguras". Em outras palavras, conseguia-se arrefecer o ânimo pelo banimento completo e imediato do asbesto, dirigindo-o ao que já era banido e/ou desinteressante do ponto de vista comercial, e garantir uns anos mais de sobrevida aos negócios da crisotila, com a legitimação internacional e tripartite estabelecida em fórum do prestígio da OIT. Daí, também, o zelo e a pressa manifestados pela Indústria brasileira, para que o Brasil fizesse o mesmo, sem perda de tempo, ao ratificar um instrumento internacional desta importância.

Como se disse no começo desta seção, o Brasil, no bojo de um suposto aperfeiçoamento da proteção da saúde e segurança dos trabalhadores, tomou a Convenção no 162 e seus complementos como escudo e legitimação da defesa da crisotila.

De fato, tanto a Lei 9.055, de 1995, como o Decreto 2.350, de 1997 (Atlas, 1999), da forma como foram redigidos, proíbem a extração, pro- 
dução, industrialização, utilização e comercialização de outras formas de asbesto, que não a crisotila, e permitem - na verdade, instituem a extração, industrialização, utilização e comercialização do asbesto/amianto da variedade crisotila, extraída no Brasil e de nosso país também exportada.

Para tanto, ambos os diplomas legais criam barreiras à importação do asbesto-crisotila, bem como à produção de fibras naturais e artificiais de qualquer origem - na família das quais estão os substitutos da crisotila, conhecidos ou potenciais, de nocividade mais baixa. Aliás, estabelece o Artigo 6o do Decreto 2.350/97, que "as fibras naturais e artificiais que já estejam sendo comercializadas ou que venham a ser fabricadas deverão ter a comprovação do nível de agravo à saúde humana avaliada e certificada pelo Ministério da Saúde, conforme critérios a serem por ele estabelecidos, no prazo de noventa dias" (Atlas, 1999:554).

Ora, não se tem conhecimento nem de que o Ministério da Saúde costumasse avaliar ou certificar alguma "comprovação do nível de agravo à saúde humana” de minérios, materiais de construção ou de produtos químicos, sintéticos ou naturais, que não sejam produtos domissanitários, medicamentos, vacinas, sangue e hemoderivados ou produtos de uso em campanhas de Saúde Pública nem, muito menos, de que este Ministério tenha feito para o asbesto-crisotila, exatamente o que se pede que faça para fibras naturais ou artificiais que a possam substituir em função de eventual nocividade inferior à do asbesto.

A política de defesa da crisotila torna-se ainda mais evidente na forma da Lei tentar direcionar a pesquisa científica e tecnológica, já que o Art. 9o determina que "os institutos, fundações e universidades públicas ou privadas e os órgãos do Sistema Único de Saúde promoverão pesquisas científicas e tecnológicas no sentido da utilização, sem riscos à saúde humana, do asbesto/amianto da variedade crisotila, bem como das fibras naturais e artificiais referidas no Art. 2 o desta lei", agregando, em seu parágrafo único, que "as pesquisas referidas no caput deste artigo contarão com linha especial de financiamento dos órgãos governamentais responsáveis pelo fomento à pesquisa científica e tecnológica" (Atlas, 1999:555) (grifo nosso), o que, aliás, já vem ocorrendo.

Neste tema, a questão da pesquisa e seu financiamento seria política e eticamente mais bem administrada, se fosse direcionada para o desenvolvimento de fibras alternativas comprovadamente não agressivas à saúde. Não é justo que o Setor Público financie a pesquisa sobre a utilização da crisotila, sobretudo quando o dispositivo legal que estabelece tal distorção embute, em seu texto, a falácia do uso da crisotila "sem riscos à saúde humana".

Vale lembrar o princípio universal de que no manejo de substâncias cancerígenas, com o potencial de malignidade que a crisotila comprovadamente tem, a garantia da ausência de riscos para a saúde humana somente é alcançada com a exposição zero, o que significa sua proibição, como já ocorre no Brasil com outras substâncias cancerígenas listadas no Anexo 13 da NR-15 (Atlas, 1999).

Assim, pelos breves exemplos que foram citados, torna-se claramente visível que, no referente à questão do asbesto, o atual posicionamento brasileiro é extremamente inadequado e inaceitável, no caso de a saúde humana, a vida e o meio ambiente constituírem, para a sociedade, valores preciosos a serem defendidos tenazmente e se esta defesa conformar efetivamente ancoradouro supremo de todas as políticas públicas de nosso país.

Em que aspectos, portanto, a atual política brasileira sobre o amianto é equivocada e insustentável?

Com o risco de repetição ou redundância, mas com a vantagem da sistematização e síntese, identificar-se-ão, no quadro a seguir, alguns dos problemas críticos:

- Pouca valorização da natureza, da gravidade e da magnitude dos problemas de saúde acometem trabalhadores expostos ao asbesto, no Brasil - Assim como foi amplamente documentado em inúmeros países do mundo ditos "desenvolvidos", também no Brasil todas as doenças relacionadas com o asbesto/amianto - em particular, asbestose, mesotelioma maligno de pleura e câncer de pulmão - já foram detectadas no país, algumas já há anos, e sua incidência tende a crescer em decorrência das exposições acumuladas e do tempo de latência habitual para estas entidades mórbidas. Ao contrário do que se tenta propalar, não há como inocentar a crisotila brasileira da gênese destes graves problemas de saúde que acometem trabalhadores, posto que a incidência destas doenças vem-se dando nos mais diferentes setores e atividades que expõem trabalhadores a este minério nocivo, principalmente trabalhadores da indústria do cimento-amianto. Em outras palavras: trabalhadores - centenas ou milhares - estão adoecendo e morrendo por doenças perfeitamente evitáveis, a maioria delas de extrema gravidade tanto pela incapacidade e sofrimento que produzem, como por sua irreversibilidade e insuscetibilidade a tratamento e alta proporção de letalidade, e isto 
não tem sensibilizado suficientemente os governantes, legisladores, políticos, empreendedores, empregadores, cientistas e outros atores sociais.

- Cultivo da ilusão ou falácia de que os problemas do amianto são de natureza meramente ocupacional, restringindo-se "apenas" a trabalhadores expostos - Assim como vem sendo documentado em inúmeros países, também no Brasil já estão sendo registrados casos de $m e$ sotelioma maligno de pleura em crianças filhos de trabalhadores e em mulheres cônjuges de trabalhadores expostos ao asbesto. Além da óbvia gravidade do fato, o equívoco principal reside na ilusão ou na falácia de que o problema da exposição ao amianto é meramente ocupacional. Ao contrário, como corretamente foi salientado em outra publicação, "não é verdade o que se afirma, pois o amianto é um problema de Saúde Pública, já que pode causar danos não somente aos trabalhadores, como também a seus familiares, vizinhos às instalações e populações não-ocupacionalmente expostas e sequer monitoradas, e ao meio ambiente, na medida em que os resíduos com amianto não podem ser destruídos, já que uma de suas tão decantadas propriedades é o fato de ser incombustível (asbesto) e incorruptível (amianto), daí vindo a origem grega e latina de seu nome, respectivamente" (Giannasi, 1994:20).

- Subestimação da ubiqüidade da exposição e visão reducionista da responsabilidade pelo controle da exposição - Como corretamente afirma a EPA, dos Estados Unidos, "as pessoas estão freqüentemente expostas ao asbesto sem o saber e raramente estão em posição de protegerem a si próprias. As fibras de asbesto geralmente são invisíveis, sem odor, muito duráveis ou persistentes, e altamente aerodinâmicas. As fibras podem se deslocar por grandes distâncias e permanecem no meio ambiente por tempo muito longo. Portanto, a exposição pode ocorrer muito tempo após a liberação da fibra de asbesto, e em local muito distante da fonte de liberação" (Percival et al., 1996:572). O equívoco principal é cultivar um conceito reducionista e falacioso de que o controle nos locais de trabalho resolveria o problema da nocividade do asbesto, centrando, portanto, na esfera do Setor Trabalho, o eixo das políticas e as ações governamentais de controle. O problema tem de ser enfocado com uma ampla perspectiva de Saúde Pública e de proteção do Meio Ambiente, muito além, portanto, das fronteiras dos estabelecimentos de trabalho; da competência da CLT, das Normas Regulamentadoras de Segurança e Medicina do Trabalho (NRs) e da fiscalização do trabalho; do âmbito das normas in- ternacionais do trabalho emanadas da OIT e assim por diante.

- Cultivo e difusão da falsa segurança de que a crisotila é inócua para a saúde, principalmente a crisotila "brasileira" - Além da bem conhecida defesa da "importância econômico-social e estratégica do amianto no contexto brasileiro" (Ferrantini et al., 1988; Nunes, 1988; Scliar, 1998; Fernandez Jr., 1999), tanto a indústria como determinados órgãos governamentais e centros de pesquisa em Engenharia e Geologia em nosso país esforçam-se em demonstrar a suposta "pureza" da crisotila brasileira, isto é, a não-contaminação por anfibólios (Cassola, 1993; Oliveira, 1996). No presente estudo demonstrou-se fartamente que a "hipótese dos anfíbólios" não se sustenta. Infelizmente asbestose, mesotelioma maligno e câncer de pulmão têm sido provocados em expostos unicamente à crisotila nas mais diferentes regiões do globo, inclusive no Brasil. Outrossim, todas estas doenças vêm sendo descritas em países que mineram crisotila de qualidade equivalente à do Brasil, como é o caso das minas da China e do Zimbábue, conforme comentado anteriormente (Cullem \& Baloyi, 1991; Frank, 1995b; Hillerdal, 1999). A demonstração experimental da baixa biopersistência de fibras de crisotila brasileira no interior do pulmão de ratos suíços (Bernstein et al., 1999), infelizmente não consegue invalidar as evidências epidemiólogicas sobre a nocividade da crisotila, no Brasil e alhures. (Dement, 1991; Dement \& Brown, 1993; Frank, 1995a; IPCS, 1998).

- Cultivo e difusão do conceito da suficiência do uso do asbesto "em condições de segurança” - Esta posição ingênua e insustentável tem, como referência máxima, a Convenção no 162 da OIT, sobre o uso do asbesto em "condições de segurança". O respeito a determinados "limites de tolerância” asseguraria a não-nocividade do asbesto em ambientes de trabalho. Contudo, até defensores da inocuidade da crisotila admitem e defendem a posição de que “... apesar do respeito a limites de tolerância muito restritivos, conseguido por meio de medidas de controle ambiental introduzidas nos locais de trabalho, casos de doença relacionados com o asbesto continuam a ocorrer, por razões de suscetibilidade pessoal (como por exemplo, proporções de retenção de fibra na árvore respiratória, acima da média), ou devido a falhas nos meios de controle, em determinadas atividades profissionais ou em determinados processos. (...) Uma não desprezível proporção de locais de trabalho ainda não respeitam os regulamentos de controle, onde eles existem, enquanto 
que em alguns países eles ainda não existem..." (Becklake, 1998:62).

- Defesa do conceito da existência de um "limite seguro de exposição" para o asbesto - crisotila - De há muito questiona-se a existência de "limites seguros de exposição" a determinadas substâncias químicas, em especial, as cancerígenas. Para o caso do asbesto-crisotila, a Comissão das Comunidades Européias foi enfática: "até o momento, não foi identificado qualquer limite permitido de exposição, abaixo do qual a crisotila não oferece risco de carcinogênese" (Commission of the European Communities, 1999:20). A avaliação de risco (risk assessment) realizada pela OSHA, nos Estados Unidos, como parte do processo de revisão dos Limites Permitidos de Exposição (PEL) ocorridos em 1986 e em 1994, mostraram que a exposição a 2 fibras $/ \mathrm{cm}^{3}$ de ar estava associada a um excesso de 64 mortes por mil trabalhadores expostos ao asbesto, ao longo de sua vida profissional. Reduzindo de 2 fibras $/ \mathrm{cm}^{3}$ para 0,2 fibra $/ \mathrm{cm}^{3}$ de ar, este risco cairia para um excesso de 6,7 mortes por mil trabalhadores. Mesmo com o limite de 0,1 fibra $/ \mathrm{cm}^{3}$, permaneceria um excesso de 3,4 mortes por mil trabalhadores. Como diz Lemen (1995:420), "mesmo com o novo limite estabelecido pela OSHA pode ser claramente visto que o risco de morrer por câncer nem é zero, nem é muito próximo a ele" (U.S. Department of Labor, 1986, 1994; Lemen, 1995). Pesquisadores reconhecidos, como o Dr. Leslie Stayner, do NIOSH, juntamente com seus colaboradores de outras instituições científicas reconhecidas, após analisarem os achados de uma das mais completas coortes de trabalhadores que se expuseram à crisotila nos Estados Unidos, são enfáticos ao afirmarem que "as estimativas de risco indicam ser apropriado controlar a exposição ao asbesto crisotila, mesmo abaixo do atual limite estabelecido pela OSHA" $\left(0,1 \mathrm{fibra} / \mathrm{cm}^{3}\right)$, posto que, "este nível ainda estaria associado a um excesso de 5 mortes por câncer de pulmão, em cada 1.000 trabalhadores expostos durante sua vida laboral, e 2 mortes por 1.000, decorrentes de asbestose" (Stayner et al., 1997:651).

- Inexistência de produtos similares mais seguros para a saúde humana - Embora seja compreensível que a indústria do amianto tente divulgar este conceito impreciso no Brasil e em outros países que mineram e exportam o asbesto-crisotila (Gibbs, 1994; Asbestos Institute, 1995), já de há muitos anos são conhecidas alternativas tecnológicas relativamente mais seguras para a saúde humana e para o meio ambiente (INSERM, 1998; Foà \& Basilico, 1999). O estudo da Comissão das Comunidades Euro- péias que antecedeu a decisão pelo banimento de todas as formas de asbesto, tomada em 1999, é explícito ao afirmar que "existem atualmente disponíveis para todas as aplicações $e$ usos remanescentes da crisotila, substitutos ou alternativas que não são classificados como cancerígenos e que são considerados menos perigosos" (Commission of the European Communities, 1999:19). Se as alternativas tecnológicas de substituição do asbesto forem consideradas insatisfatórias, é óbvio que mais investimentos em pesquisa tecnológica referida à Biologia e às Ciências da Saúde fazem-se necessárias. Com razão, o Projeto de Lei no 2.186/ 96 dos deputados Eduardo Jorge e Fernando Gabeira propõe, entre outras providências relativas ao asbesto, o redirecionamento tanto temático da pesquisa quanto político de seu financiamento, expressamente distinto do atualmente estabelecido no Parágrafo Único do Artigo 9o da Lei 9.055/95 (anteriormente criticado), que passaria a ter a seguinte redação: “Os institutos, fundações e universidades públicas promoverão pesquisa de desenvolvimento de fibras alternativas comprovadamente não agressivas à saúde coletiva, e colocarão suas tecnologias gratuitamente à disposição das empresas interessadas".

- Inacessibilidade econômica às fibras alternativas que podem substituir o amianto - Este argumento prevalente no meio político, tecnológico e econômico brasileiro utilizado em defesa da permanência do uso do asbesto-crisotila no Brasil, não se sustenta ante a necessidade urgente de revisão deste posicionamento brasileiro em direção à priorização da defesa da saúde, da vida e do meio ambiente. Ocorre que "até o momento o mercado brasileiro, dominado pelo lobbies do amianto, tem se ressentido dos custos dos produtos de substituição, já que a maioria deles ainda é importada e poucas pesquisas foram realizadas com as fibras naturais abundantes em nosso país (sisal, coco, cânhamo, juta, bagaço de cana, etc.). As grandes empresas do setor de fibrocimento chegaram a realizar pesquisas de novas tecnologias 'asbestos-free' ou 'no-asbestos', que foram totalmente abandonadas. Por outro lado, não se deve comparar diretamente preços entre amianto e os materiais alternativos, pois as composições só com amianto, como por exemplo os freios, dependendo do produto, podem chegar a ter $70 \%$, e quando substituído, já que não há um único material capaz de fazê-lo em todas as suas propriedades, os diversos materiais de substituição contribuem na composição com apenas $2 \%$ ou 3\%, o que no produto final representam acréscimos da ordem de $20 \%$ a $30 \%$ em seu custo. Por 
fim, poderíamos desmontar a argumentação de baixo custo da matéria-prima nacional, pois os preços praticados, nos moldes de outros cartéis industriais, têm sido superiores ao do amianto canadense" (Giannasi, 1994:21).

- Desemprego para os que trabalham atualmente com asbesto-crisotila - Efetivamente, se um banimento fosse intempestivamente estabelecido, sem a devida priorização da questão dos empregos, esta possibilidade poderia tornar-se real, como tem se tornado com a adoção de novas tecnologias em nosso meio. Contudo, duas medidas poderiam atenuar o eventual impacto. Primeiro: o estabelecimento de um prazo - por exemplo, 1 (um) ano para entrada em vigor da proibição da extração, industrialização e comercialização da crisotila e dos produtos que a contêm, como está proposto no Projeto de Lei no 2.186/96, acima mencionado. Segundo: o mesmo Projeto de Lei já incluiu, entre outras disposições, a criação, pelo Governo Federal, de mecanismos de incentivos fiscais às empresas atingidas pelo banimento do amianto, visando garantir-lhes reconversão tecnológica a outros ramos de atividade. Estabelece também a organização, pelo Ministério do Trabalho, de programa de treinamento especial para os trabalhadores afetados com o banimento da utilização do asbesto, de modo a recolocá-los em outras atividades produtivas.

Conclui-se esta seção com as mesmas palavras que o estudo da Comissão das Comunidades Européias termina, após analisar outras alternativas e argumentos não muito distintos dos que acima foram identificados e criticados: "um caminho efetivo para proteger a saúde humana é o da proibição do uso de fibras de crisotila e dos produtos que a contém" (Commission of the European Communities, 1999:20).

\section{Referências}

ACGIH (American Conference of Governmental Industrial Hygienists), 1999. Limites de Exposição (TLVs) para Substâncias Químicas e Agentes Físicos e Índices Biológicos de Exposição (BEIs) para 1999. São Paulo: Associação Brasileira de Higienistas Ocupacionais.

ADDISON, J., 1999. Minimising the health hazards associated with derogated products containing chrysotile asbestos. Annals of Occupational Hygiene, 43:496-498.

ALGRANTI, E., 1986. As doenças ligadas à exposição ao asbesto. Revista Brasileira de Saúde Ocupacional, 14:15-16.

ALGRANTI, E., 1988. Riscos à saúde causados pelo asbesto e o controle médico. Revista Brasileira de Saúde Ocupacional, 16:10-11.

ALGRANTI, E.; DE CAPITANI, E. M. \& BAGATIN, E., 1995. Sistema Respiratório. In: Patologia do Trabalho (R. Mendes, org.), pp. 89-137, Rio de Janeiro: Atheneu.

ALGRANTI, E.; LIMA, C. Q. \& VIEIRA, A. V., 1989. Asbesto e carcinoma broncogênico: Pesquisa de fibras em tecido pulmonar de três pacientes portadores de carcinoma broncogênico. Revista Paulista de Medicina, 107:133-138.

AMÂNCIO, J. B.; BONCIANI, M. \& URQUIZA, S. D., 1988. Avaliação radiológica de trabalhadores da indústria de fibrocimento do Estado de São Paulo. Revista Brasileira de Saúde Ocupacional, 16:5155.
ASBESTOS INSTITUTE, 1995. Asbestos-free does not mean risk-free. Asbestos Institute Newsletter, 2. $<$ http://www.asbestos-institute.ca/newsletters/ nl-95-2.html>.

ASBESTOS INSTITUTE, 1997. Politics, not science, basis for France's ban of asbestos. Asbestos Institute Newsletter, 1. <http://www.asbestos-institute.ca/ newsletters/nl.97-1.html>.

ATLAS, 1999. Segurança e Medicina do Trabalho. Manuais de Legislação Atlas 16. 43a Ed. São Paulo: Atlas.

BECKLAKE, M., 1998. Asbestos-related diseases. In: Encyclopaedia of Occupational Health and Safety (J. M. Stellman, ed.), pp. 50-63, Geneva: International Labour Office.

BEDRIKOW, B., 1989. Asbestose e tumores profissionais. Revista Paulista de Medicina, 107:131-132.

BÉGIN, R.; GAUTHIER, J. J.; DESMEULES, M. \& OSTIGUY, G., 1992. Work-related mesothelioma in Quebec, 1967-1990. American Journal of Industrial Medicine, 22:531-542.

BERNSTEIN, D. M.; ROGERS, R. A. \& THEVENAZ, P., 1999. The Inhalation Biopersistence and Morphologic Lung Disposition of Pure Chrysotile Asbestos in Rats. Vienna: Scientific Committee on Occupational Health in the Chemical Industry. (mimeo.)

BONCIANI, M., 1993. O asbesto no Brasil. In: Isto é Trabalho de Gente? Vida, Doença e Trabalho no Brasil (J. T. P. Buschinelli; L. E. Rocha \& R. M. Rigotto, org.), pp. 550-567, São Paulo: Editora Vozes. 
BRASIL, 1991. Decreto Executivo 126 de 22 de Maio de 1991. Brasília, DF: Diário Oficial da República Federativa do Brasil, 23 mai.

CASE, B. W., 1991. Health effects of tremolite. Annals of the New York Academy of Sciences, 643:491-504.

CASSOLA, M. S., 1993. Características Primárias do Amianto Crisotila de Minaçu, Goiás, e sua Influência na Qualidade do Produto Final. Dissertação de Mestrado, São Paulo: Escola Politécnica, Universidade de São Paulo.

CASTLEMAN, B., 1995. The migration of industrial hazards. International Journal of Occupational and Environmental Health, 1:85-96.

CASTLEMAN, B., 2000. RE: Call for an international ban on asbestos. American Journal of Industrial Medicine, 37:239-240.

CASTRO, H. A. \& GOMES, V. R., 1997. Doenças do aparelho respiratório relacionadas à exposição ao amianto. Revista Pulmão, 6:162-170.

CHEN, M. \& HUANG, C. L., 1997. Industrial workers' health and environmental pollution under the New International Division of Labor: The Taiwan experience. American Journal of Public Health, 87:1223-1231.

CHURG, A., 1982. Asbestos fibers and pleural plaques in an autopsy population. American Journal of Pathology, 109:79-96.

CHURG, A., 1991. Analysis of lung asbestos content. British Journal of Industrial Medicine, 48:649-652.

COLLEGIUM RAMAZZINI, 1999a. Call for an international ban on asbestos. American Journal of Industrial Medicine, 36:227-229.

COLLEGIUM RAMAZZINI, 1999b. Call for an international ban on asbestos. Scandinavian Journal of Work Environment and Health, 25:633-635.

COMMISSION OF THE EUROPEAN COMMUNITIES, 1999. Commission Directive 1999/77/EC of $26 \mathrm{Ju}-$ ly 1999, adapting to technical progress for the sixth time Annex I to Council Directive 76/769/ EEC on the approximation of the laws, regulations and administrative provisions of the Member Sates relating to restrictions on the marketing and use of certain dangerous substances and preparations (asbestos). Official Journal, L207, pp. 18-20, 6 Aug.

COOKE, W. E., 1927. Fibrosis of the lungs due to the inhalation of asbestos dust. BMJ, 11:1024-1025

COSTA, J. L. R., 1983. Estudo da Asbestose no Município de Leme-SP. Dissertação de Mestrado, Campinas: Faculdade de Ciências Médicas, Universidade Estadual de Campinas.

COSTA, J. L. R., 1984. Asbestose: Um exemplo de abordagem alternativa das doenças profissionais no Brasil. Revista Brasileira de Saúde Ocupacional, 12:2-19.

COSTA, J. L. R. \& FERREIRA Jr., Y. M., 1984. As doenças relacionadas ao asbesto (amianto). Revista Brasileira de Saúde Ocupacional, 12:21-30.

COSTA, J. L. R.; FERREIRA Jr., Y. M. \& MENDES, R., 1983. Asbesto e doença: Introdução ao problema no Brasil. Revista da Associação Médica Brasileira, 29:18-21.

CROWSON, P., 1996. Minerals Handbook 1996-97: Statistics \& Analyses of the World's Minerals Industry. New York: Stockton Press.

CULLEM, M. R. \& BALOYI, R. S., 1991. Chrysotile as- bestos and health in Zimbabwe: I. Analysis of miners and millers compensated for asbestos-related diseases since independence (1980). American Journal of Industrial Medicine, 19:161-169.

DE CAPITANI, E. M., 1994. Alterações pulmonares e pleurais causadas pela exposição ao asbestos: Uma revisão. Jornal de Pneumologia, 20 (Sup. 4): 207-218.

DE CAPITANI, E. M.; METZE, K.; FRAZATO Jr., C.; ALTEMANI, A. M. A.; ZAMBOM, L.; TORO, I. F. C. \& BAGATIN, E., 1997. Mesotelioma maligno de pleura com associação etiológica a asbesto: A propósito de três casos clínicos. Revista da Associação Médica Brasileira, 43:265-272.

DEMENT, J. M., 1991. Carcinogenicity of chrysotile asbestos: Evidence from cohort studies. Annals of the New York Academy of Sciences, 643:15-23.

DEMENT, J. M. \& BROWN, D., 1993. Cohort mortality and case-control studies of white male chrysotile asbestos textile workers. Journal of Occupational Medicine and Toxicology, 2:355-363.

DEMENT, J. M.; BROWN, D. P. \& OKUN, A., 1994. Follow-up study of chrysotile asbestos textile workers: Cohort mortality and case study analyses. American Journal of Industrial Medicine, 26:431437.

DEPARTAMENTO NACIONAL DA PRODUÇÃO MINERAL, 1956. Higiene das Minas - Asbestose. Belo Horizonte: Divisão de Fomento da Produção Mineral, Departamento Nacional da Produção Mineral.

DOLL, R., 1955. Mortality from lung cancer in asbestos workers. British Journal of Industrial Medicine, 12:81-86.

ENGLUND, A., 1995. Recent data on cancer due to asbestos in Sweden. Medicina del Lavoro, 86:435439.

FERNANDEZ Jr., M. N., 1999. Amianto - Legislação, Usos e Importância Sócio-econômica. Brasília: Departamento Nacional de Produção Mineral. (mimeo.)

FERRANTINI, V.; FERREIRA Jr., E. A. \& FARIAS, C. C., 1988. As tendências atuais no uso do asbesto no Brasil. Revista Brasileira de Saúde Ocupacional, 16:80-81.

FERREIRA Jr., Y. M., 1986. Estudo da asbestose no município de Leme-SP. Revista Brasileira de Saúde Ocupacional, 14:16-18.

FERREIRA, A. S., 1995. Alterações radiológicas de 27 pacientes expostos ao asbesto. In: Amianto: $\mathrm{Mi}$ neral Mágico ou Maldito? Ecologia Humana e Disputa Político-Econômica (C. Scliar, org.), p. 26, Belo Horizonte: CDI.

FOÀ, V. \& BASILICO, S., 1999. Caratteristiche chimico-fisiche e tossicologica delle fibre minerali artificiali. Medicina del Lavoro, 90:10-52.

FRANCE, 1996. Decree No. 96-97 of 7 February 1996 on the protection of the population against health hazards associated with exposure to asbestos in constructed buildings. International Digest of Health Legislation, 47:214.

FRANK, A. L., 1993. Global problems from exposure to asbestos. Environmental Health Perspectives Supplements, 101(Sup.3):165-167.

FRANK, A. L., 1995a. Asbestos mineralogic analysis as indicator of carcinogenic risk. Medicina del La- 
voro, 86:490-495.

FRANK, A. L., 1995b. The use of asbestos in Japan and China and malignancy related findings. Medicina del Lavoro, 86:457-460.

FRANK, A. L.; DODSON, R. F. \& WILLIAMS, G., 1998. Carcinogenic implications of the lack of tremolite in UICC reference chrysotile. American Journal of Industrial Medicine, 34:314-317.

GIANNASI, F., 1988. A legislação nacional e internacional sobre o asbesto. Revista Brasileira de Saúde Ocupacional, 16:26-31.

GIANNASI, F., 1994. O amianto no Brasil: Uso controlado ou banimento? Revista Brasileira de Saúde Ocupacional, 22:17-24.

GIANNASI, F., 1996. Mal necessário? A construção de contrapoderes no país e a experiência dos expostos. Proteção, 57:58-61.

GIANNASI, F.; ARAGÃO, J. R. M.; BONCIANI, M.; ROMANELI, S. D. T.; PRINA, L. D.; COUTINHO, M. R. C.; COLAIACOVO, W.; FERREIRA Jr., E. A.; FERRANTINI, V. \& VON KRÜGER, W. T., 1988. As condições de utilização do asbesto nas indústrias de fibrocimento do Estado de São Paulo. Revista Brasileira de Saúde Ocupacional, 16:41-50.

GIANNASI, F. \& THÉBAUD-MONY, A., 1994. Asbestos in Brazil (Sociological aspects). In: Current Asbestos Legal, Medical and Technical Research, Volume 10 of the Sourcebook on Asbestos Diseases (G. A. Peters \& B. J. Peters, eds.), pp. 283-295, New Hampshire: Butterworth.

GIANNASI, F. \& THÉBAUD-MONY, A., 1997. Occupational exposure to asbestos in Brazil. International Journal of Occupational and Environmental Health, 3:150-157.

GIBBS, G. W., 1994. Synthetic fibres and health: An overview. Jornal de Pneumologia, 20(Sup. 4):219229.

GLOYNE, S. R., 1933. The morbid anatomy and histology of asbestosis. Tubercle, 14:550-558.

GLOYNE, S. R., 1935. Two cases of squamous carcinoma of the lung occurring in asbestosis. Tubercle, 17:5-10.

GOODMAN, M.; MORGAN, R. W.; RAY, R.; MALLOY, C. D. \& ZHAO, K., 1999. Cancer in asbestos-exposed occupational cohorts: A meta-analysis. Cancer Causes and Control, 10:453-465.

GOTTLIEB, L. S., 1989. The range of medical abnormalities resulting from asbestos exposure (An overview). In: Asbestos Medical Research. Volume 4 of the Sourcebook on Asbestos Diseases: Medical, Legal and Engineering (G. A. Peters \& B. J. Peters, eds.), pp. 1-35, New York: Garland Law Publishing.

GREENBERG, M., 2000. Call for an international ban on asbestos: Trust me, I'm a doctor. American Journal of Industrial Medicine, 37:232-234.

HARINGTON, J. S., 1991. The carcinogenicity of chrysotile asbestos. Annals of the New York Academy of Sciences, 38:547-555.

HARINGTON, J. S. \& McGLASHAN, N. D., 2000. The South African asbestos trade, 1994-1999. American Journal of Industrial Medicine, 37:229.

HILLERDAL, G., 1999. First China-Japan joint asbestos symposium, Beijing, 16-17 July 1999. Scandinavian Journal of Work Environment and Health, 25:458.

HINDS, M. W., 1978. Mesotheliomas in the United
States: Incidence in the 1970s. Journal of Occupational Medicine, 20:469-471.

HUNCHAREK, M., 1994. Asbestos and cancer: Epidemiological and public health controversies. Cancer Investigation, 12:214-222.

HUUSKONEN, M. S.; KARJALAINEN, A.; TOSSAVAINEN, A. \& RANTANEN, J., 1995. Asbestos and cancer in Finland. Medicina del Lavoro, 86:426434.

IARC (International Agency for Research on Cancer), 1977. Asbestos. Lyon: IARC/World Health Organization.

INSERM (Institut National de la Santé et de la Recherche Médicale), 1997. Effects sur la Santé des Principaux Types d'Exposition à l'Amiante. Paris: INSERM.

INSERM (Institut National de la Santé et de la Recherche Médicale), 1998. Effects sur la Santé de Fibres de Substitution à l'Amiante. Paris: INSERM.

IPCS (International Programme on Chemical Safety), 1998. Chrysotile Asbestos. Geneva: World Health Organization.

JAVHOLM, L.; ENGLUND, A. \& ALBIN, A., 1990. Pleural mesothelioma in Sweden: An analysis of the incidence according to the use of asbestos. Occupational and Environmental Medicine, 56:110113.

KARJALAINEN, A., 1997. Asbestos - A continuing concern. Scandinavian Journal of Work Environment and Health, 23:81-82.

KARJALAINEN, A.; PUKKALA, E.; MATTSON, K.; TAMMILETHO, L. \& VAINIO, H., 1997. Trends in mesothelioma incidence and occupational mesotheliomas in Finland in 1960-1995. Scandinavian Journal of Work, Environment and Health, 23:266-270.

LADOU, J., 1999. The role of occupational medicine in the new industrial era. European Journal of Oncology, 4:101-110.

LEMEN, R. A., 1995. Asbestos related disease in the United States. Medicina del Lavoro, 86:411-425.

LEMEN, R. A., 2000. Call for an international ban on asbestos: Why asbestos should be banned. American Journal of Industrial Medicine, 37:236-237.

LEMEN, R. A. \& BINGHAM, E. A., 1994. A case study in avoiding a deadly legacy in developing countries. Toxicology and Industrial Health, 10:59-87.

LEVY, B. S. \& SEPLOW, A., 1992. Asbestos-related hazards in developing countries. Environmental Research, 59:167-174.

LIDDELL, F. D. K.; McDONALD, A. D. \& McDONALD, J. C., 1997. The 1891-1920 birth cohort of Quebec chrysotile miners and millers: Development from 1904 and mortality to 1992. Annals of Occupational Hygiene, 41:13-36.

LYNCH, K. M. \& SMITH, W. A., 1935. Pulmonary asbestosis. III. Carcinoma of lung in asbestos-silicosis. American Journal of Cancer, 24:56-64.

LYRA, M. A. T., 1982. Inquérito preliminar do risco de asbestose em uma indústria de lona de freio: Avaliação médica e ambiental. In: Amianto: Mineral Mágico ou Maldito? Ecologia Humana e Disputa Político-Econômica (C. Scliar, org.), p. 26, Belo Horizonte: CDI.

MAGNANI, C.; TERRACINI, B.; IVALDI, C.; MANCINI, A. \& BOTTA, M., 1996. Mortalita per tumori e altre 
cause tra i lavoratori del cemento-amianto a Casale Monferrato. Medicina del Lavoro, 87:133-146.

MALTONI, C., 1999. Call for an international ban on asbestos. Toxicology and Industrial Health, 15: 529-531.

MALTONI, C., 2000. Call for an international ban on asbestos. American Journal of Industrial Medicine, 37:230-231.

MALTONI, C.; PINTO, C. \& MOBIGLIA, A., 1991. Mesotheliomas following exposure to asbestos used in railroads: The Italian cases. Toxicology and Industrial Health, 7:1-45.

MALTONI, C.; PINTO, C.; CARNUCCIO, R.; VALENTI, P.; LODI, E. \& AMADUCCI, E., 1995a.· Mesotheliomas following exposure to asbestos used in railroads: 130 Italian cases. Medicina del Lavoro, 86:461-477.

MALTONI, C.; PINTO, C.; VALENTI, D.; CARNUCCIO, R.; AMADUCCI, E. \& MINARDI, F., 1995b. Mesotheliomas following exposure to asbestos used in sugar refineries: Report of 12 Italian cases. Medicina del Lavoro, 86:478-483.

MANCUSO, T. F., 1988. Relative risk of mesothelioma among railroad machinists exposed to chrysotile. American Journal of Industrial Medicine, 13:639657.

McDONALD, A. D. \& McDONALD, J. C., 1980. Malignant mesothelioma in North America. Cancer, 46:1650-1656.

McDONALD, J. C., 2000. Call for an international ban on asbestos: Why not ban asbestos? American Journal of Industrial Medicine, 37:235.

McDONALD, J. C.; ARMSTRONG, B. CASE, B. \& McDONALD, A. D., 1989. Mesothelioma and asbestos fiber type. Evidence from lung tissue analyses. Cancer, 63:1544-1547.

McDONALD, J. C.; LIDDELL, F. D. K.; DUFREDNE, A. \& McDONALD, A. D., 1993. The 1881-1920 birth cohort of Quebec chrysotile miners and millers: Mortality 1976-88. British Journal of Industrial Medicine, 50:1072-1081.

McDONALD, J. C.; LIDDELL, F. D. K.; GIBBS, G. W.; EYSSEN, G. E. \& McDONALD, A. D., 1980. Dust exposure and mortality in chrysotile mining, 1910-75. British Journal of Industrial Medicine, 37:11-24.

McDONALD, J. C.; McDONALD, A. D. \& HUGHES, J. M., 1999. Chrysotile, tremolite and fibrogenicity. Annals of Occupational Hygiene, 43:439-442.

MENDES, R., 1986. Doenças respiratórias ocupacionais: II. Asbestose. Jornal de Pneumologia, 12: 189-197.

MENDES, R., 1987. Atualização sobre doenças respiratórias ocupacionais. II - Asbestose. Revista Brasileira de Saúde Ocupacional, 15:7-13.

MENDONÇA, E. M. C.; ALGRANTI, E.; SILVA, R. C. C. \& BUSCHINELLI, J. T. P., 1994. Ambulatório de pneumopatias ocupacionais da Fundacentro Resultados após 10 anos. Revista Brasileira de Saúde Ocupacional, 22:7-13.

MONIZ-DE-ARAGÃO, J. R. N.; ZAVARIZ, C.; UEHARA, M. K. \& NERY, T. C. S., 1988. Estudo do uso de amianto em uma empresa. Revista Brasileira de Saúde Ocupacional, 16:37-41.

MOSSMAN, B. T.; BIGNON, J.; CORN, M.; SEATON, A. \& GEE, J. B. L., 1990. Asbestos: Scientific develop- ments and implications for public policy. Science, 247:294-301

MUSK, A. W.; DE KLERK, N. H.; ECCLES, J. L.; HOBBS, M. S. T.; ARMSTRONG, B. K.; LAYMAN, L. \& McNULTY, J. C., 1992. Wittenoom, Western Australia: A modern industrial disaster. American Journal of Industrial Medicine, 21:735-747.

NEWHOUSE, M. L. \& THOMPSON, H., 1965. Mesothelioma of pleura and peritoneum following exposure to asbestos in the London area. British Journal of Industrial Medicine, 22:261-269.

NICHOLSON, W. J., 2000. Call for an international ban on asbestos. American Journal of Industrial Medicine, 37:238.

NICHOLSON, W. J. \& LANDRIGAN, P. J., 1994. The carcinogenicity of chrysotile asbestos. Advances of Modern Environmental Toxicology, 22:407-423.

NICHOLSON, W. J. \& RAFFN, E., 1995. Recent data on cancer due to asbestos in the U.S.A. and Denmark. Medicina del Lavoro, 86:393-410.

NOGUEIRA, D. P., 1983. Asbestose: Um grave risco ainda ignorado no Brasil. Revista da Associação Médica Brasileira, 29:2.

NOGUEIRA, D. P., 1988a. La asbestosis en el Brasil: Un alerta a los países latinoamericanos. In: La Protección del Trabajo en el Mundo Moderno (G. Martin Marchesini, org.), pp. 291-297, s/l: Cardenas.

NOGUEIRA, D. P., 1988b. O asbesto e sua utilização no Brasil. Revista Brasileira de Saúde Ocupacional, 16:7-9.

NOGUEIRA, D. P.; CERTAIN, D. A.; UESUGUI, S. J.; KOGA, R. K. \& RIBEIRO, H. P., 1975. Asbestose no Brasil: Um risco ignorado. Revista de Saúde Pública, 9:427-432.

NUNES, J. S. M., 1988. Importância econômico-social e estratégica do amianto no contexto brasileiro. Revista Brasileira de Saúde Ocupacional, 16:34-37.

O ESTADO DE SÃO PAULO, 1999. Venda de amianto será proibida na Europa. O Estado de São Paulo, São Paulo, 12 mai., Caderno Geral, p. Al0.

OLIVEIRA, M. C. B., 1996. Caracterização Tecnológica do Minério de Crisotila da Mina de Cana Brava, GO. Tese de Doutorado, São Paulo: Instituto de Geociências, Universidade de São Paulo.

PERCIVAL, R. V.; MILLER, A. S.; SCHROEDER, C. H. \& LEAPE, J. P., 1996. Environmental Regulation: Law, Science, and Policy. 2nd Ed. s/1: Aspen Publishers.

PETERS, G. A. \& PETERS, B. J., 1988. A Decade of Abatement Regulations. In: Sourcebook on Asbestos Diseases: Medical, Legal and Engineering Aspects. v. 3. (G. A. Peters \& B. J. Peters, eds.), pp. 375-403. New York: Garland Law Publishing.

PIGG, B. J., 1994. The uses of chrysotile. Annals of Occupational Hygiene, 38:453-458.

QUAGLIATO Jr., R., 1980. Sessão anátomo-clínica. Jornal de Pneumologia, 2:79.

RICHTER, E. D.; BERDUGO, M.; LASTER, R.; WESTIN, J. B. \& FISCHBEIN, A., 1995. Chrysotile and crocidolite asbestos in Israel: Uses, exposures and risks. Medicina del Lavoro, 86:449-456.

SANDEN, A.; JARVHOLM, B.; LARSSON, S. \& THIRINGER, G., 1992. The risk of lung cancer and mesothelioma after cessation of asbestos exposure: A prospective cohort study of shipyard workers. European Respiratory Journal, 5:281-285. 
SANTOS, M. I. R., 1979. Asbestose, a verdade dos diagnósticos. Saúde Ocupacional e Segurança, 14:5964.

SANTOS, M. I. R. \& MACHADO, G. F., 1976. Asbestose pulmonar. Jornal de Pneumologia, 2:79.

SANTOS, M. I. R. \& MENDES, R., 1980. Doenças profissionais causadas por poeiras. IV. Asbesto. In: Medicina do Trabalho - Doenças Profissionais (R. Mendes, org.), pp. 247-259, São Paulo: Sarvier.

SCLIAR, C., 1998. Amianto: Mineral Mágico ou Maldito? Ecologia Humana e Disputa Político-Econômica. Belo Horizonte: CDI.

SELIKOFF, I. J.; CHURG, J \& HAMMOND, E. C., 1964. Asbestos exposure and neoplasia. JAMA, 188:2226.

SELIKOFF, I. J.; HAMMOND, E. C. \& SEIDMAN, H., 1979. Mortality experience of insulation workers in the United States and Canada, 1943-1976. Annals of the New York Academy of Sciences, 330:91116.

SELIKOFF, I. J. \& LEE, D. H. K., 1978. Asbestos and Disease. New York: Academic Press.

SMITH, A. H. \& WRIGHT, C. C., 1996. Chrysotile asbestos is the main cause of pleural mesothelioma. American Journal of Industrial Medicine, 30:252-266.

STAYNER, L. T.; DANKOVIC, D. A. \& LEMEN, R. A., 1996. Occupational exposure to chrysotile asbestos and cancer risk: A review of the amphibole hypothesis. American Journal of Public Health, 86:179-186.

STAYNER, L. T.; SMITH, R.; BAILER, J.; GILBERT, S.; STEENLAND, K.; DEMENT, J.; BROWN, D. \& LEMEN, R., 1997. Exposure-response analysis of risk of respiratory disease associated with occupational exposure to chrysotile asbestos. Occupational and Environmental Medicine, 54:646-652.
TEIXEIRA, M. M.; COUTINHO, M. R. \& ROMANELI, S. D. T., 1988. Medidas de segurança na manipulação das fibras e de produtos de asbesto. Revista Brasileira de Saúde Ocupacional, 16:15-25.

THÉBAUD-MONY, A., 1995. Asbestos: Science in the face of hostility in São Paulo. New Solutions, 5:6466.

U. S. DEPARTMENT OF LABOR, 1986. Final risk: Asbestos. Federal Register, 51FR, 22612, 20 Jun.

U. S. DEPARTMENT OF LABOR, 1994. Occupational exposure to asbestos: Final rule. Federal Register, 29CFR, 10 Aug. Parts 1910.1001, Sub Part Z.

U. S. DEPARTMENT OF THE INTERIOR, 1998. Minerals Yearbook. Area Reports: International 1996. Mineral Industries of Latin America and Canada. Volume III. Washington, D.C.: Government Printing Office.

WAGNER, J. C., 1986. Mesothelioma and mineral fibers. Cancer, 57:1905-1911.

WAGNER, J. C.; BERRY, G. \& TIMBRELL, V., 1973. Mesothelioma in rats after inoculation with asbestos and other materials. British Journal of Cancer, 28:173-187.

WAGNER, J. C.; SLEGGS, C. A. \& MARCHAND, P., 1960. Diffuse pleural mesothelioma and asbestos exposure in the North Western Cape Province. British Journal of Industrial Medicine, 17:260-271.

WÜNSCH FILHO, V., 1995a. Trabalho industrial e câncer de pulmão. Revista de Saúde Pública, 29:166176 .

WÜNSCH FILHO, V., 1995b. Riscos ocupacionais e câncer de pulmão. Jornal de Pneumologia, 21:3442. 